
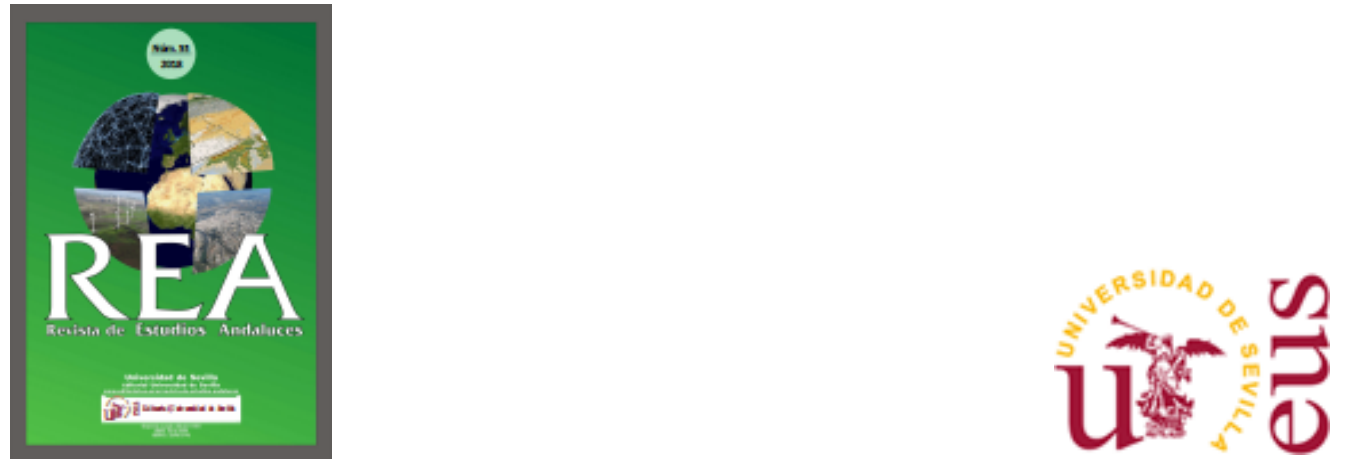

Revista de Estudios Andaluces (REA)

e-ISSN: $2340-2776$.

REA núm. 35 (2018). http://dx.doi.org/10.12795/rea.2018.i35

\title{
Autonomía Local, Organización Territorial y Segregación Municipal
}

Local Autonomy, Territorial Organization and Municipal Segregation

\section{Luis Copano-Ortiz}

Junta de Andalucía

luis.copano@geografosdeandalucia.org

Formato de cita / Citation: Copano-Ortiz, Luis (2018). Autonomía Local, Organización Territorial y Segregación Municipal. Revista de Estudios Andaluces, núm. 35, 63-100 http://dx.doi.org/10.12795/rea.2018.i35.03

Enlace artículo/to link to this article: http://dx.doi.org/10.12795/rea.2018.i35.03

\section{(c) $(1) \Theta \Theta$}




\title{
Autonomía Local, Organización Territorial y Segregación Municipal
}

\section{Local Autonomy, Territorial Organization and Municipal Segregation}

\author{
Luis Copano-Ortiz \\ Junta de Andalucía \\ luis.copano@geografosdeandalucia.org
}

Recibido: 4 de diciembre, 2017

Revisado: 9 de enero, 2018

Aceptado: 11 de enero, 2018

\section{Resumen}

La Ley 5/2010 de Autonomía Local de Andalucía profundiza en las capacidades de los municipios para decidir sobre sí mismos: los procedimientos de segregación de términos municipales necesitan conformidad expresa de la mayoría absoluta del pleno del ayuntamiento del municipio que sufre la segregación. Por otro lado, los municipios tienen la posibilidad de organizar espacialmente su término municipal, o parte de él, en circunscripciones territoriales como manifestación de su plena autonomía política, pudiendo ser de carácter desconcentrado (caseríos, parroquias, aldeas, barrios, anteiglesias, concejos, pedanías, lugares anejos y otros análogos) o descentralizado (Entidades Locales Autónomas o Entidades Vecinales). En cuanto a las Entidades Locales Autónomas conformadas en Andalucía, suelen ser un paso previo a la creación de un nuevo municipio, por lo que la Ley $27 / 2013$, de Racionalización y Sostenibilidad de la Administración Local ha fijado un límite poblacional que, en la práctica, supone acabar con las aspiraciones segregacionistas.

Palabras clave: autonomía local, segregación, entidad submunicipal, entidad local autónoma, entidad vecinal.

\section{Abstract}

The Law 5/2010 of Local Autonomy of Andalusia deepens in the capacities of the municipalities to decide on themselves: the procedures of segregation of municipal terms need express conformity of the absolute majority of the plenary session of the local government of the municipality that suffers the segregation. On the other hand, the municipalities have the possibility of spatially organizing their municipal area, or part of it, in territorial districts as a manifestation of their full political autonomy, and may be of a deconcentrated nature (hamlets, parishes, villages, neighborhoods, churches, councils, districts, adjoining and other analogous places) or decentralized

Revista de Estudios Andaluces, núm. 35 (2018) pp. 63-100. e-ISSN: 2340-2776 http://dx.doi.org/10.12795/rea.2018.i35.03

\section{cc) (i) $\ominus$}


(Autonomous Local Entities or Neighborhood Entities). As for the Autonomous Local Entities conformed in Andalusia, they are usually a previous step to the creation of a new municipality, for which the Law 27/2013, of Rationalization and Sustainability of the Local Administration has established a population limit that, in the practice, suppresses segregationist aspirations.

Keywords: local autonomy, segregation, submunicipal entities, autonomous local entity, neighborhood entity.

Revista de Estudios Andaluces, núm. 35 (2018) pp. 63-100. e-ISSN: 2340-2776

http://dx.doi.org/10.12795/rea.2018.i35.03

(c) $(i) \Theta(9)$

Esta obra se distribuye con la licencia Creative Commons Reconocimiento-NoComercialSinObraDerivada 4.0 Internacional 


\section{INTRODUCCIÓN}

Según queda recogido en la Carta Europea de la Autonomía Local (1985), la autonomía local se entiende como "el derecho y la capacidad efectiva de las Entidades locales de ordenar y gestionar una parte importante de los asuntos públicos, en el marco de la Ley, bajo su propia responsabilidad y en beneficio de sus habitantes". Este concepto adquirió relevancia legal tras la aprobación de este documento normativo, en cuanto que persigue configurar un marco común para todos los entes locales europeos, contribuyendo a la construcción europea fundamentada en alcanzar una mayor cohesión territorial, socioeconómica y normativa entre los estados miembros, basada en el respeto a los principios de democracia, participación ciudadana y descentralización del poder público.

Partiendo del hecho de que el ejercicio de las competencias públicas "debe incumbir preferentemente a las autoridades más cercanas a los ciudadanos", la Carta dice que dichas competencias "no pueden ser puestas en tela de juicio ni limitadas por otra autoridad central o regional, más que dentro del ámbito de la Ley", por lo que el reconocimiento de la autonomía local por las leyes internas de cada país y, a ser posible, por los textos constitucionales, debe ser un objetivo claro. Además, para fomentar la participación en los asuntos que afecten directamente al ámbito local pero que no sean competencia de las entidades locales, estas "deben ser consultadas, en la medida de lo posible, a su debido tiempo y de forma apropiada, a lo largo de los procesos de planificación y de decisión". Esta autonomía queda reflejada en el artículo 6.1 , en el que se concede a las entidades locales plena capacidad para "definir por sí mismas las estructuras administrativas internas con las que pretenden dotarse, con objeto de adaptarlas a sus necesidades específicas y a fin de permitir una gestión eficaz".

La reforma del Estatuto de Autonomía para Andalucía, aprobada mediante Ley Orgánica 2/2007, de 19 de marzo, supone, además, la consolidación del municipalismo, como símbolo de garantía y protección de la autonomía local. El artículo 92.2 reconoce a los municipios competencias propias y el artículo 192.1 establece que una ley regulará la participación de las entidades locales en los tributos de la Comunidad Autónoma. Por su parte, el artículo 98 hace una remisión expresa a una nueva ley de régimen local para regular, entre otras materias, aquellas que se deduzcan de su artículo 60, concretadas en su apartado 1.b), donde se dice que es competencia exclusiva de la Comunidad Autónoma, en materia de régimen local, la determinación de las competencias y potestades propias de los municipios y demás entes locales, de conformidad con el Título III (referido a la organización territorial de la Comunidad Autónoma).

Revista de Estudios Andaluces, núm. 35 (2018) pp. 63- 100. e-ISSN: 2340-2776 http://dx.doi.org/10.12795/rea.2018.i35.03 (c) (i) () SinObraDerivada 4.0 Internacional 
Asentadas las bases legales para el desarrollo del concepto de autonomía local, se aprobaría la Ley 5/2010, de 11 de junio, de Autonomía Local de Andalucía (LAULA), cuyos contenidos ahondan en las capacidades de los municipios para decidir sobre sí mismos:

- se concreta el procedimiento para la segregación ${ }^{1}$ de términos municipales, cuya creación de nuevos municipios tendrá carácter excepcional, realizándose sobre la base de núcleos de población y necesitando, además de la conformidad expresa, acordada por mayoría absoluta, del pleno del ayuntamiento del municipio que sufre la segregación, la concurrencia de una serie de circunstancias históricas, sociales, económicas, geográficas, etc..

- los municipios tienen la posibilidad de organizar espacialmente su término municipal, o parte de él, en circunscripciones territoriales como manifestación de su plena autonomía política, con el fin de acercar la acción administrativa a la población, facilitar la participación ciudadana y dotar de mayor eficacia a la prestación de servicios.

Podríamos considerar que el municipio tiene plena libertad para establecer o no circunscripciones territoriales en su término municipal en función de esta capacidad potestativa que le otorga el artículo 91.3 de la Ley Orgánica 2/2007, de Reforma del Estatuto de Autonomía de Andalucía, y como manifestación de su plena autonomía política. En este sentido, en el artículo 90 del Estatuto vigente, se establecen los principios de organización territorial andaluza, que deberán regirse "por los principios de autonomía, responsabilidad, cooperación, desconcentración, descentralización, subsidiariedad, coordinación, suficiencia financiera y lealtad institucional". Estos principios deben ser aplicados en todos los elementos de la estructura territorial andaluza, que está compuesta por los municipios, provincias y demás entes territoriales locales.

No obstante, el municipio, como entidad territorial básica (artículo 91.1 del Estatuto y artículo 3.2 de la LAULA), tiene que aplicar el principio de organización territorial de Andalucía anteriormente mencionado que, si bien el artículo 109 de la LAULA parece plantear que la organización territorial del municipio es simplemente una posibilidad que le otorga la Ley en función del ejercicio de su potestad de autoorganización, se establece, para las entidades territoriales, de forma expresa, que deberán regirse, entre otros, por los principios de desconcentración y descentralización. Por tanto, a pesar de que la potestad de autoorganización territorial corresponde al municipio, este

\footnotetext{
${ }^{1}$ Se entiende por segregación de un término municipal la separación de parte de su territorio, bien para la creación de uno distinto o bien para ser agregado a otro preexistente, limítrofe y de la misma provincia, no comportando, en este último caso, creación ni supresión de municipios (art. 93.1 de la LAULA).
}

Revista de Estudios Andaluces, núm. 35 (2018) pp. 63-100. e-ISSN: 2340-2776 http://dx.doi.org/10.12795/rea.2018.i35.03

(c) (i) $\Theta \odot$

cc) SinObraDerivada 4.0 Internacional 
deberá (mandato) valorar las posibilidades de organizarse espacialmente en circunscripciones territoriales que podrán ser desconcentradas y/o descentralizadas.

Esta posibilidad ya era una obligación para aquellos municipios encuadrados en el régimen de organización de los municipios de gran población, puesto que la Ley $57 / 2003$, de 16 de diciembre, de medidas para la modernización del gobierno local, que introducía en la Ley $7 / 1985$, Reguladora de las Bases del Régimen Local (LRBRL) su título $X$, exigía la creación de los distritos como divisiones territoriales de la totalidad del municipio, por lo que debían tener sus propios órganos de gestión desconcentrada para fomentar la participación ciudadana en los asuntos municipales.

\section{METODOLOGÍA Y APROXIMACIÓN NORMATIVA}

Para abordar con éxito la disertación relativa al concepto de la autonomía local y la organización territorial del municipio en Andalucía ha sido necesario recurrir a dos documentos inéditos que se enmarcan dentro del ámbito competencial de la Dirección General de Administración Local de la Junta de Andalucía: "La demarcación municipal en Andalucía" y "El componente espacial del municipio y su administración a la luz de la potestad de autoorganización" (Medina, J.A., inédito), en los que se hace hincapié en los conceptos de autonomía local, demarcación municipal y administración del territorio; así como al artículo científico denominado "Las Entidades Locales Autónomas en la Ley de Autonomía Local de Andalucía (LAULA)" (Pérez, M.M., 2010).

También ha sido fundamental conocer al detalle la legislación actualmente en vigor, principalmente la Ley 7/1985, de 2 de abril, de Bases del Régimen Local y la Ley 5/2010, de 11 de junio, de Autonomía Local de Andalucía, que derogó la Ley 7/1993, de 27 de julio, Reguladora de la Demarcación Municipal de Andalucía, y modificó su reglamento (Decreto 185/2005, de 30 de agosto, por el que se aprueba el Reglamento de Demarcación Municipal de Andalucía y del Registro Andaluz de Entidades Locales), así como la Ley 27/2013, de 27 de diciembre, de Racionalización y Sostenibilidad de la Administración Local.

\subsection{NORMATIVA GENERAL DE RÉGIMEN LOCAL}

Con la nueva configuración territorial del Estado tras la Constitución de 1978, y tras el fracaso del Proyecto de Ley de Bases de 1981, era necesario que el Estado definiera las líneas maestras normativas de Régimen Local para que las comunidades autónomas pudieran desarrollar en sus leyes autonómicas las facultades que, en materia de Administración Local, estaban recogidas en sus respectivos estatutos de autonomía.

Revista de Estudios Andaluces, núm. 35 (2018) pp. 63- 100. e-ISSN: 2340-2776

http://dx.doi.org/10.12795/rea.2018.i35.03

(c) $($ ) $(8)$

SinObraDerivada 4.0 Internacional 
La Ley 7/1985, de 2 de abril, Reguladora de las Bases de Régimen Local (LRBRL), en su artículo $3^{2}$, establecía la distinción entre Entidades Locales Territoriales (municipio, provincia e isla) y otras Entidades Locales que no tenían tal carácter territorial (las Entidades de Ámbito Territorial Inferior al Municipio ${ }^{3}$, las comarcas, las áreas metropolitanas y las mancomunidades de municipios). Respecto a las entidades submunicipales, la normativa concreta que la condición de Entidades Locales se alcanza en aquellos casos en que hayan sido instituidas o reconocidas por las comunidades autónomas, conforme al artículo 45 de la Ley ${ }^{4}$, por lo que no aclara la situación jurídica de las Entidades Locales Menores reconocidas con anterioridad.

Las leyes de las comunidades autónomas sobre Régimen Local regularán las Entidades de Ámbito Territorial Inferior al Municipio (EATIMES) para la gestión descentralizada de núcleos de población separados, bajo su denominación tradicional de caseríos, parroquias, aldeas, barrios, anteiglesias, concejos, pedanías, lugares anejos y otros análogos, o aquella que establezcan las leyes (art. 45) ${ }^{5}$. De esta forma, las leyes autonómicas podrán establecer otras denominaciones; habilitación que ha dado como resultado una gran diversidad de nombres entre las distintas comunidades autónomas ${ }^{6}$ (Entidad Local Autónoma en Andalucía; Entidad Local Menor en Aragón, Cantabria, Castilla y León, Comunidad de Madrid, Comunitat Valenciana, Illes Balears, Extremadura, Galicia, La Rioja, País Vasco y Región de Murcia; Entidad de Ámbito Territorial Inferior al Municipio en Castilla-La Mancha; Entidad Municipal Descentralizada en Cataluña; Parroquia Rural en el Principado de Asturias; y Concejo en la Comunidad Foral de Navarra).

Estas Entidades Locales, al no ser territoriales, sino institucionales, se configuran en función del principio de descentralización administrativa consagrado en el artículo 103 de la Constitución de 1978. Por tanto, no estamos ante entes naturales creados jurídicamente per se, por sus características peculiares de distancia al núcleo urbano de la capitalidad del municipio, o por el número de habitantes de su población, que le

\footnotetext{
2 El apartado número 2 del artículo 3 ha sido modificado por el número 2 del artículo 1o de la Ley 27/2013, 27 diciembre, de Racionalización y Sostenibilidad de la Administración Local (B.O.E. 30 diciembre), dejando de ser consideradas las EATIMES de nueva creación como Entidades Locales.

3 De nuevo se produce un cambio de denominación de los núcleos de población separados del municipio, abandonándose el de Entidad Local Menor, usado desde 1924, e incorporándose el nuevo de Entidad de Ámbito Territorial Inferior al Municipio (EATIM).

${ }^{4}$ Este artículo establece que la iniciativa para la constitución de una nueva EATIM debe corresponder indistintamente a la población interesada o al ayuntamiento correspondiente.

${ }^{5}$ Artículo 45 dejado sin contenido por el número 14 del artículo 1 o de la Ley 27/2013, 27 diciembre, de Racionalización y Sostenibilidad de la Administración Local (B.O.E. 30 diciembre).

${ }^{6}$ En el caso de Canarias, no existen entidades para la gestión descentralizada de núcleos de población separados. La Disposición Adicional Segunda de la Ley 7-2015, de 1 de abril, de los municipios de Canarias, recoge la posibilidad que tiene el Ayuntamiento de Teguise de constituir una entidad de gestión desconcentrada en el núcleo poblacional de la isla de La Graciosa, puesto que representa intereses peculiares que hacen conveniente una gestión diferenciada del resto del municipio.
}

Revista de Estudios Andaluces, núm. 35 (2018) pp. 63-100. e-ISSN: 2340-2776

http://dx.doi.org/10.12795/rea.2018.i35.03

(c) (i) $\Theta \odot$

(c) 1 EY $\Theta$ Esta obra se distribuye con la licencia Creative Commons Reconocimiento-NoComercialSinObraDerivada 4.0 Internacional 
puedan hacer considerarse casi un municipio. Para la LRBRL, estos elementos no eran lo esencial para la creación de las EATIMES. La única y verdadera esencia era conseguir el objetivo de prestar a todos los ciudadanos del término municipal el mismo nivel de servicios, y, para ello, la descentralización administrativa institucional es la herramienta adecuada.

Por otro lado, en lo relativo a la gestión desconcentrada de núcleos de población separados, se menciona que para "facilitar la participación ciudadana en la gestión de los asuntos locales y mejorar ésta, los Municipios podrán establecer órganos territoriales de gestión desconcentrada, con la organización, funciones y competencias que cada Ayuntamiento les confiera, atendiendo a las características del asentamiento de la población en el término municipal, sin perjuicio de la unidad de gobierno y gestión del Municipio" (art. 24).

Por último, hay que recordar que la creación de nuevos municipios ${ }^{7}$ solo podrá realizarse a partir de la existencia de núcleos de población territorialmente diferenciados y siempre que los municipios resultantes contaran con suficientes recursos para el cumplimiento de sus competencias y no supusieran una disminución de la calidad de servicios que venían siendo prestados a la población (art. 13.2). No obstante, las competencias sobre creación, supresión y alteración de términos municipales estarán reguladas por la legislación de las comunidades autónomas sobre Régimen Local (art. 13.1), aunque requiriendo la audiencia de los municipios interesados y dictamen del Consejo de Estado o de los organismos respectivos de las autonomías, en cuyo caso deben dar conocimiento a la Administración del Estado.

La Disposición Final Primera de la Ley 7/1985 autorizó al Gobierno para refundir en un solo texto las disposiciones legales vigentes en materia de Régimen Local, de acuerdo con lo indicado en su disposición derogatoria, en cuanto no se opusieran, contradijeran o resultasen incompatibles con las disposiciones de dicha Ley. De esta forma, el Real Decreto Legislativo 781/86, de 18 de abril, por el que se aprueba el Texto Refundido de las Disposiciones Legales vigentes en materia de Régimen Local (TRDLRL), desarrolla más ampliamente el régimen jurídico de las EATIMES, en sus artículos 38 a 45. Sin embargo, estos artículos no tienen carácter básico, de acuerdo con la Disposición Final Séptima del mismo Texto.

En lo referido a las competencias que podrán ser asumidas por estas Entidades, siguen vigentes las reguladas por el Decreto de 16 de diciembre de 1950 por el que se aprueba el texto articulado de la Ley de Régimen Local de 17 de julio de 1945 (art. 38).

\footnotetext{
${ }^{7}$ El Artículo 13 quedará modificado por la redacción del número 5 del artículo 1 o de la Ley 27/2013, 27 diciembre, de Racionalización y Sostenibilidad de la Administración Local (B.O.E. 30 diciembre).
}

Revista de Estudios Andaluces, núm. 35 (2018) pp. 63- 100. e-ISSN: 2340-2776 http://dx.doi.org/10.12795/rea.2018.i35.03 (c) (1) (9) SinObraDerivada 4.0 Internacional 
En este Texto Refundido se concreta la situación jurídica de las entidades locales submunicipales reconocidas con anterioridad a esta normativa; de este modo, se regula, acorde con el nuevo modelo competencial, la modificación y supresión de las EATIMES mediante dos vías: por petición de la propia Entidad cumpliendo una serie de requisitos 8 o por acuerdo del Consejo de Gobierno de la respectiva Comunidad Autónoma, adoptado previa audiencia de las Entidades y Ayuntamientos interesados.

En cuanto a la desconcentración administrativa, se establece que en "cada uno de los poblados y barriadas separados del casco urbano y que no constituyan Entidad local, el Alcalde podrá nombrar un representante personal entre los vecinos residentes en el mismo" (art. 20).

Para la segregación de parte del territorio de uno o varios municipios para constituir otro independiente (art. 6), se utiliza una redacción similar a la de la Ley de 1945 de Bases de Régimen Local, concretando que "podrá realizarse cuando existan motivos permanentes de interés público, relacionados con la colonización interior, explotación de minas, instalación de nuevas industrias, creación de regadíos, obras públicas u otras análogas".

Posteriormente, el Real Decreto 1690/1986, de 11 de julio, por el que se aprueba el Reglamento de Población y Demarcación Territorial de las Entidades Locales, actualiza las normas reglamentarias que estuvieran vigentes, en especial el reglamento, con denominación homónima, de 1952. Llama la atención que ya en el artículo 1.4. se haga mención expresa a la competencia que tienen los ayuntamientos para la división de su término municipal en distritos y barrios, así como las posibles variaciones que pudieran acontecer.

Todo lo concerniente a las EATIMES queda regulado en el Capítulo $V$, recogiéndose lo establecido por la LRBRL, y manteniéndose lo relativo a la constitución de las mismas y al establecimiento de los límites territoriales en función del Reglamento de 1952.

Así, por un lado, los núcleos de población separados ${ }^{9}$, bajo una denominación tradicional, con características peculiares dentro de un municipio, podrán constituir Entidades de Ámbito Territorial Inferior al Municipio: "cuando se suprima el municipio a que pertenezcan, cuando por tratarse de núcleos urbanos de nueva creación se considere necesario dotarlos de administración propia, cuando por alteración de los términos municipales pasen dichos núcleos a formar parte de otros municipios y

\footnotetext{
${ }^{8}$ Estos requisitos se concretan en el artículo 42: petición escrita de la mayoría de los vecinos residentes en el territorio que haya de ser base de la Entidad, o alternativamente acuerdo del ayuntamiento, información pública vecinal, informe del ayuntamiento y resolución definitiva por el Consejo de Gobierno de la comunidad autónoma.

${ }^{9}$ Denominaciones recogidas en el artículo 45 de la Ley 7/1985, de 2 de abril, Reguladora de las Bases de Régimen Local (LRBRL).
}

Revista de Estudios Andaluces, núm. 35 (2018) pp. 63-100. e-ISSN: 2340-2776

http://dx.doi.org/10.12795/rea.2018.i35.03

(c) $(i) \odot$

(c) SinObraDerivada 4.0 Internacional 
cuando las fincas adquiridas para colonización interior no reúnan los requisitos exigidos para constituir municipio, pero sean asiento permanente de un núcleo de población".

Y por otra parte, para determinar el territorio de aquellas entidades que no lo tuvieren delimitado con anterioridad, se tendrán en cuenta, dentro de lo posible, las siguientes normas: "cuando se trate de una parroquia rural constituida los límites serán los mismos que tenga la parroquia que haya servido de base a su reconocimiento legal, según la demarcación eclesiástica vigente; en el caso de un Concejo abierto de carácter tradicional o de un antiguo Municipio anexionado a otro, el territorio propio será, respectivamente, el que correspondiera al ámbito territorial del Concejo abierto o al primitivo término municipal anexionado; para núcleos urbanos o rurales que no tengan las características de los anteriores, el ámbito territorial de la nueva Entidad estará referido al casco de la parroquia, lugar, aldea, anteiglesia, barrio, anejo, u otro grupo semejante $y$, además, a los terrenos circundantes que posean o cultiven los vecinos de la Entidad o constituyan el patrimonio de ésta, siempre que pueda establecerse fácilmente la línea divisoria entre esos terrenos y los que pertenezcan a los núcleos intermedios; y, en los demás casos el Ayuntamiento deberá asignar a la nueva Entidad el ámbito territorial que sea preciso para el cumplimiento de sus fines".

Este Reglamento quedará modificado, en su Título II relativo a la población y al padrón de habitantes, por el Real Decreto 2612/1996 de 20 de diciembre, el cual obliga a los ayuntamientos a revisar, al menos una vez al año, la relación de entidades y núcleos de población existentes, así como su división en secciones (art. 76), por lo que todo el término municipal debe quedar dividido en entidades singulares y colectivas, así como núcleos de población y diseminados, según las normas establecidas en la Resolución de 9 a abril de 1997 en la que se dictan instrucciones técnicas a los ayuntamientos sobre la gestión y revisión del padrón municipal.

Con la ley 57/2003 de medidas para la modernización del Gobierno Local se produce la ruptura con la tendencia al uniformismo existente en el Régimen Local, por el cual no se había tenido en cuenta el volumen demográfico municipal para establecer un régimen jurídico diferenciado que hiciera frente a la elevada complejidad de las ciudades más pobladas. De esta forma, se adiciona el título $X$ en la LRBRL, estableciéndose un régimen orgánico específico (art. 121) dirigido a los municipios de gran población. Se convierte en una exigencia, común a todos los municipios regulados este régimen, la delimitación administrativa local (art. 128) para la creación de distritos "como divisiones territoriales propias, dotadas de órganos de gestión desconcentrada, para impulsar y desarrollar la participación ciudadana en la gestión de los asuntos municipales y su mejora, sin perjuicio de la unidad de gobierno y gestión del municipio".

Revista de Estudios Andaluces, núm. 35 (2018) pp. 63- 100. e-ISSN: 2340-2776 http://dx.doi.org/10.12795/rea.2018.i35.03 
Para concluir, es necesario hacer referencia a la Ley 27/2013 de Racionalización y Sostenibilidad de la Administración Local, puesto que supone una modificación sustancial del estatus legal de las EATIMES, ya que aquellas de nueva creación dejarán de tener personalidad jurídica, considerándose ahora al mismo nivel que los órganos de gestión desconcentrada, por lo que no pueden tener competencias propias.

Y no solo se queda ahí, ya que limita la autonomía de los municipios respecto a la creación de nuevas entidades, que solo podrán ser creadas cuando se concluya que es la forma "más eficiente para la administración desconcentrada de núcleos de población separados de acuerdo con los principios previstos en la Ley Orgánica 2/2012, de 27 de abril, de Estabilidad Presupuestaria y Sostenibilidad Financiera".

En cuanto a la creación de nuevos municipios se adiciona, en el apartado 2 del artículo 13 de la LRBRL, un límite demográfico mínimo de 5.000 habitantes, y un límite económico mediante la obligatoriedad de que los nuevos municipios sean "financieramente sostenibles". Este hecho motivó que durante la tramitación administrativa de una serie de iniciativas de creación de nuevos municipios, cuyas iniciativas segregacionistas tuvieron entrada en la Administración con anterioridad al 31 de diciembre de 2013, se suscitara un debate jurídico acerca de la procedencia o no de exigir un mínimo poblacional en los núcleos sobre los que se proyectaba la segregación, lo que conllevó la ralentización de los correspondientes procedimientos hasta que la cuestión quedó solventada.

\subsection{NORMATIVA AUTONÓMICA ANDALUZA DE RÉGIMEN LOCAL}

\subsubsection{LA LEY REGULADORA DE LA DEMARCACIÓN MUNICIPAL DE ANDALUCÍA (LRDMA) Y SU DESARROLLO REGLAMENTARIO}

El Estatuto de Autonomía de Andalucía de 1981 venía a integrar y completar lo ya recogido por la Constitución Española referido a la Administración Local y entidades locales (Título Preliminar, artículos 3, 4 y 5), definiendo al municipio como la entidad territorial básica de la Comunidad Autónoma y fijando las pautas generales que deben regir los procesos de alteración de términos municipales y fusión de municipios limítrofes.

No obstante, será la Ley 7/1993, de 27 de julio, Reguladora de la Demarcación Municipal de Andalucía (LRDMA) la normativa que retomaría el espinoso tema de las modificaciones de términos municipales (Título II): para las fusiones se evitan aquellas medidas coercitivas que pudieran forzar a una pérdida de representatividad política de núcleos de población en beneficio del supuesto de funcionalidad y, en cuanto a las segregaciones, se trata de garantizar la eficacia alterando lo menos posible la realidad municipal existente, por lo que se fijaron unos mínimos de población y distancia del

Revista de Estudios Andaluces, núm. 35 (2018) pp. 63-100. e-ISSN: 2340-2776 http://dx.doi.org/10.12795/rea.2018.i35.03

(c) (i) $(9)$

cc) SinObraDerivada 4.0 Internacional 
núcleo del que se pretendía la segregación que avalaran la viabilidad de aquel en el supuesto de que se culminara el proceso de independencia.

Por otro lado, haciendo uso de la habilitación contenida en el artículo 45 de la LRBRL, se estableció en su título $V$, artículos 47 al 70, el régimen jurídico de las Entidades que viene a denominar como "Entidades Locales Autónomas"10" y que, como también indica, pueden mantener denominaciones tradicionales como pedanías, villas, aldeas 0 cualquier otra de reconocida implantación en el lugar.

Para su constitución (art. 47.2) era necesario la existencia de un núcleo separado con "características peculiares de orden histórico, patrimonial, económico o cualesquiera otras que permitan identificar unos intereses netamente diferenciados". No se establecía un umbral mínimo poblacional o distancia respecto al núcleo principal (art. 47.3), aunque dependía de las previsiones de política territorial regional, siendo necesario acuerdo del Consejo de Gobierno, que "deberá pronunciarse expresamente sobre sus límites territoriales, separación patrimonial que corresponda, competencias propias asumidas y las correspondientes asignaciones presupuestarias" (art. 51).

Estas Entidades podían asumir competencias propias (descentralización) o delegadas (desconcentración). En cuanto a las primeras (art. 53.1), se encontrarían: concesión de licencias de obras menores; pavimentación, conservación y reparación de vías urbanas; alumbrado público; limpieza viaria; ferias y fiestas locales; abastos; servicios funerarios; abastecimiento domiciliario de agua potable; alcantarillado; recogida de residuos; y control de alimentos y bebidas. Se regulaba la delegación de competencias (art. 53.2 y 54) sobre las juntas vecinales de estas Entidades "de acuerdo con su capacidad y en atención a la mayor proximidad de la gestión administrativa respecto a los ciudadanos", siempre dentro del ámbito territorial de la propia Entidad, debiéndose realizar por medio de acuerdos municipales, que "deberán precisar las facultades que se transfieren o delegan, las directrices y objetivos que deban observarse en su ejercicio, los medios que se traspasan y los mecanismos de vigilancia y control que se reserva el municipio", así como una "valoración económica del coste efectivo de los servicios objeto del mismo".

Para el desarrollo normativo de la LRDMA, se aprobó el Decreto 185/2005, de 30 de agosto, por el que se aprueba el Reglamento de Demarcación Municipal de Andalucía y

\footnotetext{
10 Se entendía mayoritariamente que las antiguas Entidades Locales Menores, que pasaron a denominarse por la LRBRL, Entidades de Ámbito Territorial Inferior al Municipio (EATIMES), ahora la Comunidad Autónoma andaluza pasaba a denominarlas Entidades Locales Autónomas (ELA). Esta doctrina encontró su oposición en la que mantenía que las ELA eran otros entes diferenciados de las EATIMES, por lo que, para alcanzar el régimen de ELA, era necesario que la EATIM se sometiera a un procedimiento de adaptación.
}

Revista de Estudios Andaluces, núm. 35 (2018) pp. 63- 100. e-ISSN: 2340-2776 http://dx.doi.org/10.12795/rea.2018.i35.03 (c) (i) (9) SinObraDerivada 4.0 Internacional 
del Registro Andaluz de Entidades Locales ${ }^{11}$, que establecía los requisitos para la creación de nuevos municipios por segregación, quedando bien definidos y desarrollados en el artículo 13 del Reglamento, evitando las ambigüedades existentes en el artículo 8 de la LRDMA, siendo necesaria la concurrencia de las siguientes circunstancias: la existencia de motivos permanentes de interés público, relacionados con la Ordenación del Territorio de Andalucía; la existencia de una identidad diferenciada por razones históricas, sociales, económicas, laborales, geográficas o urbanísticas; población no inferior a 4.000 habitantes; la existencia de una franja de suelo no urbanizable de más de 7,5 kilómetros entre los núcleos de población del municipio matriz respecto a los núcleos del municipio a segregar; que el nuevo municipio cuente con un territorio y una disponibilidad de recursos suficientes para el cumplimiento de las competencias municipales y la prestación de servicios a un mayor nivel de calidad; así como que el municipio matriz no se vea perjudicado de tal forma que disminuya la cantidad y calidad de servicios de su competencia o se vea privado de los recursos necesarios para la prestación de los servicios mínimos establecidos legalmente. En cuanto a las segregaciones sobre la base de territorios constituidos por ELA, se entiende que ya existe una identidad propia y diferenciada, rebajándose los requisitos cuantitativos relativos a la población (no inferior a 2.500 habitantes) y a la separación entre núcleos (5 kilómetros).

En cuanto a los requisitos exigidos para la constitución de Entidades Locales Autónomas (art. 45.1), la normativa concretaba los siguientes aspectos: existencia de núcleos poblacionales separados de aquel donde tiene su sede el ayuntamiento (requisito territorial); concurrencia de características de orden histórico, patrimonial, económico, etc., que permitan identificar unos intereses particulares y diferenciados respecto al resto del municipio (requisito identitario); población igual o superior a 1.000 habitantes y que en los últimos 3 años su dinámica demográfica haya sido estable o positiva (requisito demográfico); la constitución de la nueva Entidad debe implicar una mejora en la calidad de los servicios públicos que se vienen prestando, sin llevar aparejada una mayor presión fiscal sobre su población (requisito económico).

Además, deben valorarse una serie de criterios (art. 45.2) como son la inexistencia de un servicio de "transporte regular colectivo público urbano de viajeros" que conecte el núcleo principal con el núcleo o núcleos que deban constituir la base de la Entidad, así como la inexistencia de órganos de gestión desconcentrados.

El acuerdo por el que debe resolverse el procedimiento de creación de una Entidad Local Autónoma adoptará la forma de Decreto (art. 53.1), debiendo pronunciarse

\footnotetext{
${ }^{11}$ Mediante Disposición Derogatoria quedarán derogadas todas cuantas disposiciones de igual o inferior rango se opusieran a lo previsto en el presente Reglamento, especialmente la Orden de la Consejería de Gobernación de 13 de junio de 1997 que regulaba el proceso de adaptación de las Entidades de Ámbito Territorial Inferior al Municipio en Entidades Locales Autónomas.
}

Revista de Estudios Andaluces, núm. 35 (2018) pp. 63-100. e-ISSN: 2340-2776 http://dx.doi.org/10.12795/rea.2018.i35.03

(c) (i) $\Theta \odot$

(c) SinObraDerivada 4.0 Internacional 
expresamente sobre, entre otras cuestiones, nombre y capitalidad, población, delimitación territorial mediante descripción literal y cartografía, competencias propias y aquellas que vayan a delegarse, asignación presupuestaria a cargo del municipio y fórmula de actualización para futuros ejercicios, separación patrimonial, etc.

En cuanto al "territorio vecinal", que se define como el ámbito espacial donde las Entidades Locales Autónomas ejercen sus competencias (art 3.2), debe ser continuo y delimitado en función de los siguientes requisitos (art. 65): se extenderá sobre los terrenos circundantes que pertenezcan a la población de los núcleos o núcleos que conformen la Entidad; será suficiente para que se puedan ejercer las competencias asumidas; deberá tener en cuenta las expectativas de desarrollo de suelo urbano recogidas en la ordenación territorial y en la planificación urbanística; siempre que sea posible se delimitará teniendo en cuenta los accidentes geográficos o elementos de carácter permanente que sean fácilmente identificables sobre el terreno; debiendo utilizarse en todo caso un criterio restrictivo en atención a la naturaleza urbana de sus competencias.

Además, incorporó una nueva regulación sobre la adaptación de las EATIMES en ELA, desarrollando dos procedimientos diferenciados: uno simplificado (art. 78) para aquellos casos en los que existiera una delimitación territorial y separación patrimonial precisas, tuvieran concretadas sus competencias propias y delegadas y asignados fondos municipales para su ejercicio; y otro ordinario (art. 79), para aquellos casos en los que no se tuvieran claros los extremos expresados anteriormente, requiriendo de una memoria.

Si una finalidad de la LRDMA fue poner limitaciones al procedimiento de segregación para la creación de un nuevo municipio a solo aquellos casos que fueran estrictamente necesarios, el resultado se mostró eficaz, pues durante su período de vigencia solo prosperó uno de los pocos procedimientos iniciados con tal finalidad ${ }^{12}$.

\subsubsection{LA LEY DE AUTONOMÍA LOCAL DE ANDALUCÍA (LAULA)}

En el Título VII de la Ley de Autonomía Local de Andalucía (2010), dedicado a la administración del territorio municipal, se ofrece uno de los mayores signos de

12 En concreto la creación del municipio de Villanueva de la Concepción por segregación del de Antequera (Málaga), si bien, posteriormente, Balanegra se independizará de Berja (Almería) en el año 2015 estando ya derogada la LRDMA.

Revista de Estudios Andaluces, núm. 35 (2018) pp. 63- 100. e-ISSN: 2340-2776

http://dx.doi.org/10.12795/rea.2018.i35.03 (c) (i) (3) 
coherencia normativa ${ }^{13}$ con el postulado de autonomía local que da nombre a esta Ley, al reconducir la existencia de un tipo de entidad local (las denominadas, por el artículo 45 de la LRBRL -1985-, Entidades de Ámbito Inferior al Municipio, y por la LRDMA -1993-, Entidades Locales Autónomas) a la única posición posible que les depara la conceptuación del municipio como entidad local básica y con garantía constitucional, quedando totalmente dependiente de las decisiones que se tomen al respecto desde la autoridad local.

Se consideró necesario realizar una modificación en cuanto a la organización territorial del municipio y, sobre todo, en relación a las Entidades Locales Autónomas, siendo importante aclarar que las entidades locales submunicipales eran entes dirigidos al ejercicio de competencias de titularidad municipal, pues cualquier otra interpretación sería contradictoria con el principio de autonomía municipal, que es la gran línea conductora de la LAULA.

Desde esta perspectiva, sería casi más conveniente recurrir al instrumento de la delegación de competencias desde el ente municipal al de ámbito inferior. El problema radicaba, por un lado, en cómo acometer la distorsión de la dinámica generada por la Ley $7 / 1993$ (que en la práctica ha generado cuasi municipios que viven dentro de otros o en algunos casos, y lo que es peor, totalmente al margen de estos) y, por otro, en la configuración de la representatividad democrática de primer grado que ostentan los órganos de gobierno y administración de tales entidades, que les hace merecedoras de una capacidad política de más largo alcance que la simple delegación de competencias.

Debido a estas razones, pareció conveniente que la nueva Ley les siguiera atribuyendo competencias propias (artículo 123), pero que estas fueran de mera gestión de servicios públicos o de ejercicio de competencias de titularidad municipal (de forma análoga a lo que se pretende formular en la relación municipio-provincia, pero en sentido descendente). En relación a esta idea se enumeran (artículo 122) las potestades que poseen las Entidades Locales Autónomas, adecuándolas a la posición que tienen dentro del municipio.

En este sentido, parecía lógico pensar que si las competencias que le son propias son de simple gestión de servicios públicos municipales, sería necesario modificar profundamente el sistema de creación de estas entidades, alejándolas de la decisión política de la Comunidad Autónoma andaluza e interiorizándola en la voluntad del propio municipio en el que radiquen. Era fundamental conceder al propio ayuntamiento la competencia para crear (y, por tanto, suprimir, y en parte configurar) este tipo de entidades territoriales submunicipales. De otra manera, la autonomía

\footnotetext{
${ }^{13}$ Según lo expuesto por expertos juristas, si bien nos parece que su fundamento radica de las dificultades de aplicación tanto de la Ley 7/1993 como del Decreto 185/2005 de Reglamento de Demarcación Municipal de Andalucía y Registro Andaluz Entidades Locales.
}

Revista de Estudios Andaluces, núm. 35 (2018) pp. 63-100. e-ISSN: 2340-2776 http://dx.doi.org/10.12795/rea.2018.i35.03

(c) $\odot \circledast \ominus$

cc) Esta obra se distribuye con la licencia Creative Commons Reconocimiento-NoComercialSinObraDerivada 4.0 Internacional 
municipal se vería disminuida al no poder tener la última decisión sobre las competencias propias en parte de su propio término municipal.

De esta forma, el artículo 109 de la Ley de Autonomía Local establece que el municipio "podrá organizar espacialmente el término municipal, o parte de él, en circunscripciones territoriales", ya sean éstas de carácter desconcentrado (distritos, barrios, aldeas, pedanías u otras denominaciones) o descentralizado (se introduce un nuevo concepto, el de Entidades de Gestión Descentralizada para referirse a las Entidades Locales Autónomas y a las Entidades Vecinales), estando "presidida por el principio de racionalidad y economía administrativa". Deben valorarse "fundamentalmente los criterios de volumen de población, situación geográfica, necesidades sociales, diferenciación histórica y cultural, orientación de las actividades económicas más significativas y existencia de intereses peculiares de cada zona, velando, en todo caso, por el mantenimiento o consecución de la solidaridad del conjunto de la comunidad vecinal y el acceso en condiciones de igualdad a los servicios públicos de todos los vecinos y vecinas con independencia de su lugar de residencia".

Además, el artículo 116 permite a los municipios tener plena capacidad para la creación de estas circunscripciones territoriales, mencionando que "para la aprobación de la creación de la nueva entidad habrá de obtenerse el voto de la mayoría absoluta del número legal de miembros del pleno del ayuntamiento", contraponiéndose así al principio inspirador y regulador de la Ley de Demarcación Municipal de Andalucía que, en su artículo 48, exponía que "las Entidades Locales Autónomas se crearán por acuerdo Consejo de Gobierno de la Junta de Andalucía".

No obstante, la LAULA debería haber realizado algunas objeciones al principio general, puesto que según el artículo 59 de la Ley 2/2007, de Reforma del Estatuto de Autonomía de Andalucía, se concreta la competencia exclusiva de la Comunidad Autónoma sobre la organización territorial incluyendo "la determinación, la creación, la modificación, la supresión de las entidades que configuran la organización territorial de Andalucía". En el artículo 89 sobre la estructura territorial se concreta que "Andalucía se organiza territorialmente en municipios, provincias y demás entidades territoriales que puedan crearse por Ley". Por tanto, dentro de la organización territorial andaluza debemos encuadrar a las Entidades Locales Autónomas, así como a las Entidades Vecinales. A su vez, el Estatuto andaluz determina como competencias exclusivas el de la ordenación del territorio, que incluye, entre otras cuestiones, la promoción del equilibrio territorial, siendo básico para alcanzarlo, poseer cierta capacidad competencial en materia de organización submunicipal.

En definitiva, estamos de acuerdo en que la competencia sobre organización territorial de los municipios debe recaer en ellos, motivada por el principio de autonomía política

Revista de Estudios Andaluces, núm. 35 (2018) pp. 63- 100. e-ISSN: 2340-2776 http://dx.doi.org/10.12795/rea.2018.i35.03 
local. No obstante, la Comunidad Autónoma debería haberse reservado el derecho legal de actuar de oficio en determinadas situaciones que pudieran favorecer al equilibrio territorial de Andalucía. Estamos pensando en aquellos municipios con gran extensión superficial y que cuentan con un gran volumen de población situada lejos del núcleo principal $y$, en los que de acuerdo con una adecuada ordenación territorial, sería conveniente la creación de entidades (ya no nos limitamos a las ELA sino a cualquier figura tanto desconcentrada como descentralizada) siempre y cuando existiera una iniciativa vecinal consolidada de la población interesada.

Las circunscripciones territoriales desconcentradas carecen de personalidad jurídica y pueden extenderse sobre núcleos completos de población o sobre partes de alguno de ellos. De la misma manera, y aunque no lo explicite la norma, pueden crearse para la gestión indiferenciada de todos los asuntos municipales o para los de un área de acción determinada (Medina, J.A., inédito). Se trata de lo que se conocen por distritos, barrios, pedanías u otras denominaciones análogas. Y para desarrollar las funciones administrativas que se le encomienden (siempre en régimen de delegación) se les dotará de órganos representativos y de la estructura administrativa de personal o unidades administrativas que en cada momento se entiendan necesarias (artículo 111).

Al contrario de lo que sucede con las anteriores, las circunscripciones territoriales de gestión descentralizada son configuradas por la LAULA como verdaderas entidades locales $\mathrm{y}$, por consiguiente, con personalidad jurídica propia distinta de la del municipio. Aunque entre las opciones barajadas en la elaboración de la norma hubiera podido tener entrada su concepción como mera entidad instrumental dependiente o vinculada del municipio, la realidad preexistente y la pervivencia de los artículos 3.2.a) y 45 LRBRL, fundamentalmente, debieron inclinar finalmente al legislador por la utilización de la expresión "entidad local" en el artículo 113.2 y 3 a la hora de caracterizar a las figuras que se regulan en esta última norma ${ }^{14}$.

Si se analizan las leyes autonómicas de Régimen Local, la mayor parte solo contempla un tipo de ente local referido a un núcleo de población separado de la capitalidad del municipio, es decir, lo que la Ley de Bases define como Entidad de Ámbito Territorial Inferior al Municipio que, tal como ya se ha comentado, adquiere distintas denominaciones en las diversas comunidades autónomas aunque, en su mayoría, mantienen el antiguo concepto de Entidad Local Menor. Sin embargo, la LAULA recoge, dentro de las denominadas como Entidades de Gestión Descentralizada, a las Entidades Locales Autónomas y a las Entidades Vecinales.

\footnotetext{
14 Hay que recordar que, por medio de la Ley 27/2013, de 27 de diciembre, de Racionalización y Sostenibilidad de la Administración Local, estas Entidades dejan de estar consideradas como Entidades Locales.
}

Revista de Estudios Andaluces, núm. 35 (2018) pp. 63-100. e-ISSN: 2340-2776 http://dx.doi.org/10.12795/rea.2018.i35.03

(c) (i) $\Theta \odot$

(c) SinObraDerivada 4.0 Internacional 
Las Entidades Vecinales se definen en la LAULA como "entidades locales para la gestión descentralizada de servicios locales de interés general y ejecución de obras de la competencia municipal que asumen por delegación del ayuntamiento" (art. 113.2). Debemos entender que poseen competencias descentralizadas en cuanto a servicios locales de interés general, si bien no se aclara la tipología de dichos servicios. Por otro lado, se asignan competencias delegadas para la ejecución de obras de competencia municipal, por lo que podríamos hablar de una gestión mixta. El objetivo es encauzar a las futuras iniciativas vecinales que reivindiquen un cierto grado de autonomía local, hacia esta figura legal que supone un nivel inferior de competencias descentralizadas en relación a las Entidades Locales Autónomas, si bien, hasta el momento, no se ha constituido ninguna entidad bajo esta denominación.

La actual Ley no acota los requisitos mínimos indispensables para la constitución de las entidades descentralizadas, como lo hacía la anterior legislación (LRDMA), y solo se refiere de una manera muy genérica (en su artículo 112) a la existencia de "varios núcleos de población separados de aquel en que se halle la capitalidad del municipio" cuando "tuviesen características geográficas, sociales, históricas, culturales o administrativas comunes que de forma notoria revelasen unos intereses colectivos peculiares que hiciesen conveniente una gestión diferenciada del resto del municipio" (Copano, L., et al., 2013).

\section{RESULTADOS}

\subsection{ORGANIZACIÓN Y DELIMITACIÓN DE LAS ENTIDADES LOCALES AUTÓNOMAS}

El surgimiento de la figura de la Entidad de Ámbito Territorial Inferior al Municipio (EATIM) tiene su origen en la Ley municipal de 20 de agosto de 1870, que regulaba en su artículo 85, y siguientes, un sistema peculiar de organización y administración de los pueblos agregados a un término municipal, que podrían disponer de una junta de hasta cinco miembros para su administración particular; si bien su denominación proviene de la Ley 7/1985, de 2 de abril, Reguladora de las Bases de Régimen Local (LRBRL), normativa que modificaba la designación de los núcleos de población separados del municipio, abandonándose el apelativo de Entidad Local Menor, usado desde el Estatuto Municipal de Calvo Sotelo de 1924, e incorporándose la nueva denominación de Entidad de Ámbito Territorial Inferior al Municipio (EATIM).

El nacimiento de este tipo de demarcación local surgía de la necesidad de dar una dimensión mínima al municipio y de salvaguardar los derechos de ciertos núcleos de población que poseían un territorio determinado y unos bienes que querían mantenerse como privativos de esa comunidad, y que en aplicación del Título $\mathrm{VI}$ de la Constitución de 1812, dedicado al Gobierno interior de las provincias y de los pueblos,

Revista de Estudios Andaluces, núm. 35 (2018) pp. 63- 100. e-ISSN: 2340-2776 http://dx.doi.org/10.12795/rea.2018.i35.03

\footnotetext{
(c) (i) () SinObraDerivada 4.0 Internacional
} 
habían perdido tal condición, ya que se establecía, en su pretensión de homogeneizar los diferentes regímenes municipales, que "se pondrá Ayuntamiento en los pueblos que no lo tengan y en que convenga le haya, no pudiendo dejar de haberle en los que por sí o con su comarca lleguen a las mil almas y también se les señalará término correspondiente". Por tanto, y como norma general, se estableció que los pueblos que no superasen el número de 1.000 almas no podían tener ayuntamiento propio y, por tanto, estas pequeñas comunidades o núcleos aislados tenían que pasar a depender de un municipio determinado (Pallarès, A., 2009).

En Andalucía, por medio de la Ley 7/1993, de 27 de julio, Reguladora de la Demarcación Municipal de Andalucía, estas entidades submunicipales pasarían a denominarse como Entidades Locales Autónomas, manteniéndose tal denominación en la legislación actual, ya que la Ley 5/2010 de Autonomía Local de Andalucía, en su Disposición Transitoria Segunda, establece que "las entidades locales autónomas existentes a la entrada en vigor de la presente ley y que se hubieren constituido bajo la vigencia de la Ley 7/1993, de 27 de julio, Reguladora de la Demarcación Municipal de Andalucía, y aquellas otras entidades de ámbito inferior al municipio que se hubiesen constituido conforme a normativas anteriores, se regirán por lo dispuesto en la presente ley. No obstante, mantendrán, si fuese el caso, el nivel de competencias y recursos de que dispusiesen si fuesen en algún aspecto superior al contemplado en esta Ley".

Se pueden distinguir dos tipos de Entidades Locales Autónomas en función de la definición de un territorio sobre el que ejercer sus competencias:

a) aquellas que poseen un ámbito territorial concretado mediante publicación oficial por parte de la Junta de Andalucía,

b) y aquellas otras ausentes de un territorio bien delimitado en el que ejercer de forma efectiva sus funciones. El legislador andaluz no tuvo en cuenta que para la correcta gestión de competencias propias y/o delegadas, aparte de la determinación de las mismas, era necesario establecer unos límites físicos o territoriales, por lo que no exigió a los municipios que, en un plazo concreto, establecieran un ámbito territorial para aquellas ELA que no lo tuvieran asignado.

Esta necesidad, sin embargo, es una cuestión que viene determinada por Ley. Así el artículo 116 de la LAULA, relativo a la aprobación de la creación de entidades descentralizadas (por tanto, debemos considerar que las entidades vecinales también deben poseerlo), en su apartado f), indica que el estatuto de creación de la entidad debe contener como mínimo, entre otras cuestiones, el "ámbito territorial en que haya de ejercitar las competencias".

Revista de Estudios Andaluces, núm. 35 (2018) pp. 63-100. e-ISSN: 2340-2776

http://dx.doi.org/10.12795/rea.2018.i35.03

(c) (i) $(9)$ 
Según puede observarse en los cuadros 1 y $2^{15}$ y en el mapa 1 , existen un total de 42 Entidades Locales Autónomas en Andalucía ${ }^{16}$, de las que 23 poseen una delimitación territorial oficial aprobada mediante Decreto, Orden o Resolución de la Junta de Andalucía, y 19 están aún a la espera de poder disponer de una concreción espacial oficial sobre la que ejercer sus competencias, ya que no se encuentra publicada en documento oficial alguno.

Respecto a las primeras, es decir, las ELA que tienen asignado de forma oficial un territorio, podemos concluir, si se observan los cuadros 1 y 2, que la extensión superficial que poseen es bastante variada, siendo sus valores extremos los de la localidad de Bácor-Olivar con 66,94 km², perteneciente al municipio de Guadix (Granada), y Zahara de los Atunes (Barbate -Cádiz-) con tan solo $0,87 \mathrm{~km}^{2}$, seguido por La Redondela (Isla Cristina) con $2,66 \mathrm{~km}^{2}$, estando la media en $25,8 \mathrm{~km}^{2}$, lo que demuestra que la delimitación territorial de las mismas no se determina para satisfacer competencias exclusivamente urbanas, sino que se considera que debe poseer un territorio bastante más amplio que permita la viabilidad económica de la entidad, siempre y cuando no esté en perjuicio del municipio al que pertenece.

Si nos atenemos a las últimas entidades constituidas, El Turro y Bobadilla Estación, se constata que no se ha tenido en cuenta un criterio restrictivo para su delimitación, ya que cuentan con 9,16 y $46,48 \mathrm{~km}^{2}$ respectivamente. En el primer caso, la superficie territorial de El Turro, sin ser muy extensa y estar muy por debajo de la media, supone el 23,78\% del término municipal de Cacín, por lo que una delimitación mayor hubiera estado en detrimento de los recursos económicos y patrimoniales del resto del municipio. En cuanto a Bobadilla Estación, su mayor extensión territorial se debe a que el término municipal de Antequera es mucho más amplio que el de Cacín, correspondiéndole algo más del $6 \%$ del territorio antequerano.

En cuanto a las ELA sin ámbito territorial oficial ${ }^{17}$, en la práctica han estado ejerciendo sus funciones legales sobre su suelo urbano e incluso sobre un territorio más amplio no recogido en normativa legal, lo que supone, en primer lugar, una problemática asociada a la gestión de sus funciones $y$, por otro lado, un incumplimiento de las

\footnotetext{
${ }^{15}$ En cuanto a las extensiones recogidas en este cuadro, hay que tener en cuenta que no todas son oficiales y una buena parte son aproximaciones realizadas a partir de información procedente del DERA (Datos Espaciales de Referencia de Andalucía) y del Registro Andaluz de Entidades Locales.

${ }^{16}$ Existían otras 7 ELA en Andalucía que han obtenido recientemente su condición de municipio (Balanegra, Dehesas Viejas, Domingo Pérez, Játar, Montecorto, Serrato y Valderrubio) que poseían una delimitación territorial (a excepción de Balanegra) (ver cuadro 4). Además, en el año 2013, la entidad poblacional de San Julián, perteneciente al municipio de Marmolejo (Jaén), perdió su condición de ELA por inviabilidad económica e incumplimiento sistemático de los fines para los que fue constituida.

${ }^{17}$ Forman parte de este grupo las entidades que en los cuadros 1 y 2 figuran en el campo "Territorio" con el valor "No definido".
}

Revista de Estudios Andaluces, núm. 35 (2018) pp. 63- 100. e-ISSN: 2340-2776 http://dx.doi.org/10.12795/rea.2018.i35.03 (c) (i) (9) SinObraDerivada 4.0 Internacional 
Cuadro 1. Listado de Entidades Locales Autónomas en Andalucía (I).

\begin{tabular}{|c|c|c|c|c|c|c|c|c|}
\hline PROVINCIA & MUNICIPIO & ELA & TERRITORIO & CONSTITUCIÓN OFICIAL & TIPO DELIMITACIÓN & $\mathrm{KM}^{2}$ & $\begin{array}{l}\text { FUENTE } \\
\left(K^{2}\right)^{2}\end{array}$ & $\begin{array}{c}\% \\
\text { MUNICIPIO }\end{array}$ \\
\hline Almería & Fondón & Fuente Victoria & No definido & Acuerdo 27/08/1982 (ELM) & - & 39,61 & DERA & 43,48 \\
\hline \multirow{11}{*}{ Cádiz } & Barbate & Zahara de los Atunes & $\begin{array}{l}\text { Límites } \\
\text { definidos }\end{array}$ & Decreto 204/2011 (ELA) & Descripción y coordenadas (Decreto 204/2011) & 0,87 & RAEELL & 0,61 \\
\hline & \multirow{7}{*}{ Jerez de la Frontera } & La Barca de la Florida & No definido & Decreto 22/03/1957 (ELM) & Área de influencia (Decreto 22/03/1957) & 20,36 & RAEELL & 1,71 \\
\hline & & Estella del Marqués & $\begin{array}{l}\text { Límites } \\
\text { definidos }\end{array}$ & Decreto 2190/1971 (ELM) & Descripción (Decreto 2190/1971) & 15,18 & RAEELL & 1,28 \\
\hline & & Guadalcacín & No definido & Decreto 26/04/1957 (ELM) & Área de influencia (Decreto 26/04/1957) & 17,24 & RAEELL & 1,45 \\
\hline & & Nueva Jarilla & $\begin{array}{l}\text { Límites } \\
\text { definidos }\end{array}$ & Decreto 2191/1971 (ELM) & Descripción (Decreto 2191/1971) & 30,41 & RAEELL & 2,56 \\
\hline & & San Isidro del Guadalete & No definido & Decreto 22/03/1957 (ELM) & Área de influencia (Decreto 22/03/1957) & 7,97 & RAEELL & 0,67 \\
\hline & & El Torno & No definido & Decreto 10/05/1957 (ELM) & Área de influencia (Decreto 10/05/1957) & 8,20 & RAEELL & 0,69 \\
\hline & & Torrecera & No definido & Decreto 08/03/1957 (ELM) & Área de influencia (Decreto 08/03/1957) & 11,07 & RAEELL & 0,93 \\
\hline & $\begin{array}{l}\text { Jimena de la } \\
\text { Frontera }\end{array}$ & San Martín del Tesorillo & $\begin{array}{l}\text { Límites } \\
\text { definidos }\end{array}$ & Decreto 94/1999 (ELA) & Descripción (Decreto 94/1999) & 48,57 & RAEELL & 14,05 \\
\hline & \multirow{2}{*}{ Tarifa } & Facinas & No definido & Resolución 11/12/1990 (EATIM) & - & 113,28 & DERA & 27,00 \\
\hline & & Tahivilla & No definido & Decreto 26/10/1956 (ELM) & Área de influencia (Decreto 26/10/1956) & 59,28 & DERA & 14,13 \\
\hline \multirow{6}{*}{ Córdoba } & Adamuz & Algallarín & No definido & Decreto 24/01/1958 (ELM) & - & 7,49 & DERA & 2,24 \\
\hline & Córdoba & Encinarejo de Córdoba & No definido & Decreto 05/04/1957 (ELM) & Área de influencia (Decreto 05/04/1957) & 5,19 & DERA & 0,41 \\
\hline & \multirow{2}{*}{ Fuente Palmera } & Fuente Carreteros & No definido & Resolución 07/03/1989 (EATIM) & - & 8,08 & DERA & 10,81 \\
\hline & & Ochavillo del Río & $\begin{array}{l}\text { Límites } \\
\text { definidos }\end{array}$ & Decreto 286/2009 (ELA) & Descripción (Decreto 286/2009) & 5,73 & DERA & 7,67 \\
\hline & Priego de Córdoba & Castil de Campos & $\begin{array}{l}\text { Límites } \\
\text { definidos }\end{array}$ & Decreto 148/2001 (ELA) & Descripción (Decreto 148/2001) & 18,89 & RAEELL & 6,56 \\
\hline & Santaella & La Guijarrosa & $\begin{array}{l}\text { Límites } \\
\text { definidos }\end{array}$ & Decreto 215/2006 (ELA) & $\begin{array}{l}\text { Descripción, mapa y coordenadas (Decreto } \\
\text { 215/2006) }\end{array}$ & 45,56 & RAEELL & 16,78 \\
\hline
\end{tabular}

Revista de Estudios Andaluces, núm. 35 (2018) pp. 63-100. e-ISSN: 2340-2776

http://dx.doi.org/10.12795/rea.2018.i35.03

(c) $($ ) (2) 


\begin{tabular}{|c|c|c|c|c|c|c|c|c|}
\hline \multirow{3}{*}{ Granada } & Alhama de Granada & Ventas de Zafarraya & $\begin{array}{l}\text { Límites } \\
\text { definidos }\end{array}$ & Decreto 73/2002 (ELA) & Descripción (Decreto 73/2002) & 24,17 & RAEELL & 5,58 \\
\hline & Arenas del Rey & Fornes & No definido & Resolución 11/07/1989 (EATIM) & - & 16,90 & RAEELL & 15,80 \\
\hline & Cacín & El Turro & $\begin{array}{l}\text { Límites } \\
\text { definidos }\end{array}$ & Resolución 14/01/2013 (ELA) & Descripción (Resolución 14/01/2013) & 9,16 & RAEELL & 23,14 \\
\hline
\end{tabular}

Fuente: Elaboración propia a partir del Registro Andaluz de Entidades Locales (RAEELL), disposiciones de creación de las ELA y DERA (2017).

Revista de Estudios Andaluces, núm. 35 (2018) pp. 63- 100. e-ISSN: 2340-2776

http://dx.doi.org/10.12795/rea.2018.i35.03

(c) (1) (2) Es 
Cuadro 2. Listado de Entidades Locales Autónomas en Andalucía (II).

\begin{tabular}{|c|c|c|c|c|c|c|c|c|}
\hline PROVINCIA & MUNICIPIO & ELA & TERRITORIO & CONSTITUCIÓN OFICIAL & TIPO DELIMITACIÓN & $\mathrm{KM}^{2}$ & $\begin{array}{l}\text { FUENTE } \\
\left(\mathrm{KM}^{2}\right)\end{array}$ & \% MUNICIPIO \\
\hline \multirow{5}{*}{ Granada } & Guadix & Bácor-Olivar & Límites definidos & Resolución 06/07/1993 (EATIM) & Descripción (Orden 01/12/1994) & 66,94 & DERA & 20,66 \\
\hline & \multirow{2}{*}{ Motril } & Torrenueva & Límites definidos & Acuerdo 14/07/1987 (EATIM) & Descripción y mapa (Orden 28/07/1993) & 6,54 & DERA & 5,95 \\
\hline & & $\begin{array}{l}\text { Carchuna- } \\
\text { Calahonda }\end{array}$ & Límites definidos & Decreto 60/2005 (ELA) & Descripción y mapa (Decreto 60/2005) & 14,19 & RAEELL & 12,92 \\
\hline & \multirow{2}{*}{ Nevada } & Picena & No definido & Resolución 17/01/1990 (EATIM) & - & 10,34 & DERA & 13,38 \\
\hline & & Mairena & No definido & Resolución 17/01/1990 (EATIM) & - & 27,98 & RAEELL & 36,22 \\
\hline \multirow{3}{*}{ Huelva } & Alosno & Tharsis & Límites definidos & Acuerdo 25/11/1987 (EATIM) & Descripción y mapa (Orden 09/06/1993) & 58,24 & DERA & 30,41 \\
\hline & Calañas & $\begin{array}{l}\text { La Zarza- } \\
\text { Perrunal }\end{array}$ & Límites definidos & Resolución 30/03/1993 (EATIM) & Descripción y mapa (Orden 05/06/1997) & 45,09 & DERA & 15,93 \\
\hline & Isla Cristina & La Redondela & Límites definidos & Real Decreto 624/1982 (ELM) & Descripción y mapa (Decreto 163/2006) & 2,66 & RAEELL & 30,42 \\
\hline \multirow{9}{*}{ Jaén } & Alcalá la Real & Mures & Límites definidos & Decreto 116/2001 (ELA) & Descripción (Decreto 116/2001) & 15,11 & DERA & 5,78 \\
\hline & Alcaudete & La Bobadilla & Límites definidos & Decreto 221/2005 (ELA) & Descripción (Decreto 221/2005) & 41,16 & DERA & 17,39 \\
\hline & \multirow{2}{*}{ Andújar } & La Ropera & No definido & Decreto 23/11/1956 (ELM) & $\begin{array}{lccc}\text { Área de } & \text { influencia } & \text { (Decreto } \\
23 / 11 / 1956) & & \end{array}$ & 7,79 & DERA & 0,81 \\
\hline & & Los Villares & No definido & Decreto 23/11/1956 (ELM) & $\begin{array}{l}\text { Área de } \\
73 / 11 / 1956)\end{array}$ & 13,88 & DERA & 1,44 \\
\hline & Baños de la Encina & El Centenillo & No definido & Orden 30/05/1940 (ELM) & - & 0,19 & RAEELL & 0,05 \\
\hline & Linares & $\begin{array}{l}\text { Estación } \\
\text { linares-Baeza }\end{array}$ & Límites definidos & Acuerdo 19/03/1986 (EATIM) & Descripción (Orden 30/06/1987) & 21,18 & DERA & 10,78 \\
\hline & Rus & El Mármol & No definido & $\begin{array}{l}\text { ¿Estatuto de Calvo Sotelo de } \\
\text { 1974? }\end{array}$ & - & 11,48 & DERA & 24,29 \\
\hline & Villanueva de la Reina & La Quintería & No definido & Decreto 23/11/1956 (ELM) & $\begin{array}{l}\text { Área de influencia (Decreto } \\
23 / 11 / 1956)\end{array}$ & 6,72 & DERA & 3,21 \\
\hline & Bédmar y Garcíez & Garcíez & Límites definidos & Decreto 283/2003 (ELA) & Descripción (Decreto 283/2003) & 17,00 & RAEELL & 14,32 \\
\hline Málaga & Antequera & $\begin{array}{l}\text { Bobadilla } \\
\text { Estación }\end{array}$ & Límites definidos & Resolución 03/03/2014 (ELA) & $\begin{array}{l}\text { Descripción, mapa y coordenadas } \\
\text { (Resolución 03/03/2014) }\end{array}$ & 46,48 & RAEELL & 6,20 \\
\hline Sevilla & $\begin{array}{l}\text { Las Cabezas de San } \\
\text { luan }\end{array}$ & Marismillas & Límites definidos & Decreto 56/1999 (ELA) & Descripción (Decreto 56/1999) & 12,21 & DERA & 5,31 \\
\hline
\end{tabular}

Revista de Estudios Andaluces, núm. 35 (2018) pp. 63-100. e-ISSN: 2340-2776

http://dx.doi.org/10.12795/rea.2018.i35.03

c) (1) (9) Esta obra se distribuye con la licencia Creative Commons Reconocimiento-NoComercial-SinObraDerivada 4.0 Internacional 


\begin{tabular}{|l|l|l|l|l|l|l|l|}
\hline \multirow{2}{*}{ Écija } & $\begin{array}{l}\text { Isla Redonda- } \\
\text { La Aceñuela }\end{array}$ & Límites definidos & Decreto 95/1999 (ELA) & Descripción (Decreto 95/1999) \\
\cline { 2 - 6 } & $\begin{array}{l}\text { El Palmar de } \\
\text { Troya }\end{array}$ & Límites definidos & Decreto 60/2003 (ELA) & Descripción y mapa (Decreto 60/2003) & 36,49 & RAEELL \\
\hline
\end{tabular}

Fuente: Elaboración propia a partir del Registro Andaluz de Entidades Locales (RAEELL), disposiciones de creación de las ELA y DERA (2017).

Revista de Estudios Andaluces, núm. 35 (2018) pp. 63- 100. e-ISSN: 2340-2776

http://dx.doi.org/10.12795/rea.2018.i35.03

(c) (1) $(9)$ Esta obra se distribuye con la licencia Creative Commons Reconocimiento-NoComercial-SinObraDerivada 4.0 Internacional 
Mapa 1. Territorio de las Entidades Locales Autónomas de Andalucía.

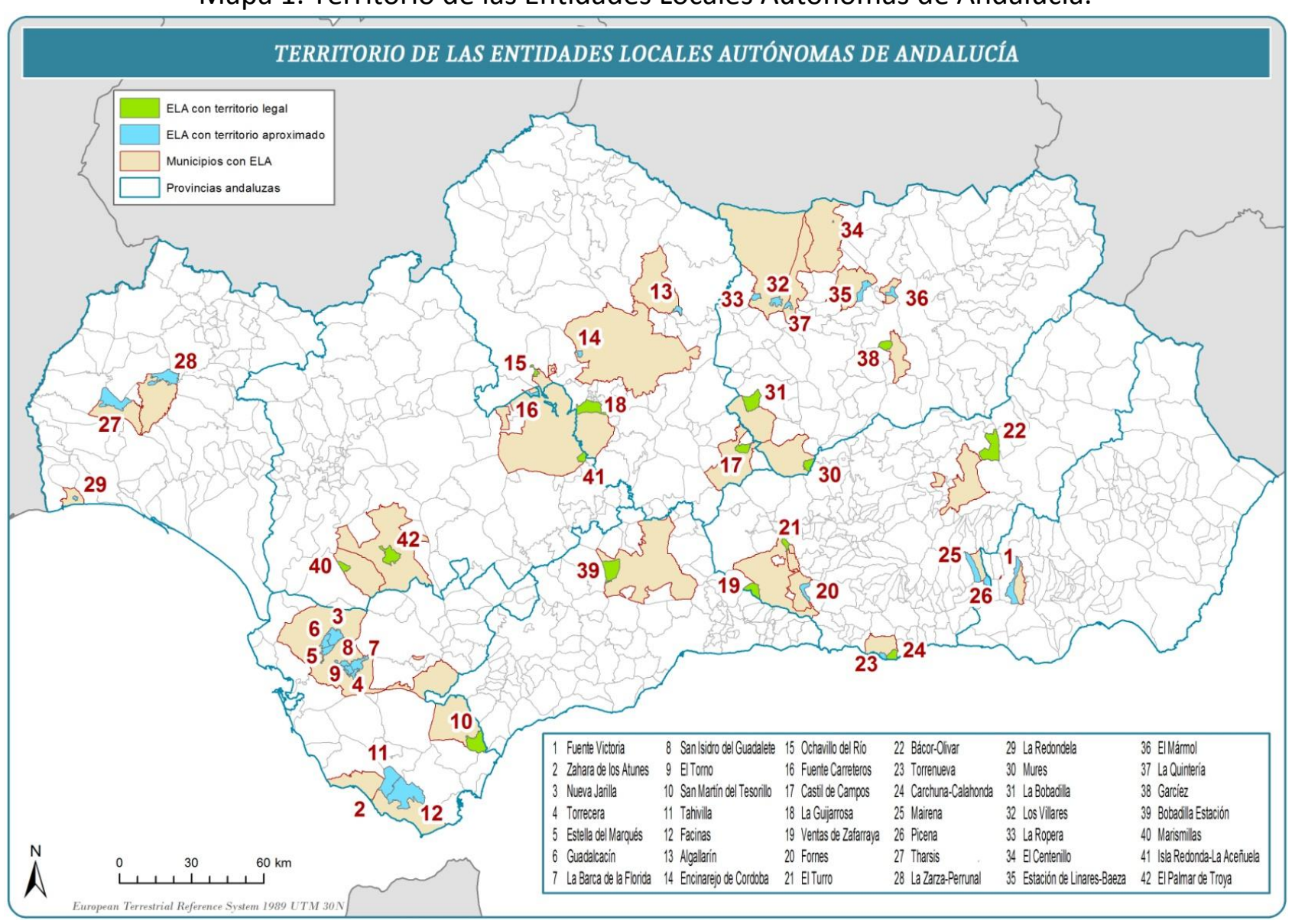

Fuente: Actualización a partir de Copano, L., et al. (2013) y DERA (2017).

Revista de Estudios Andaluces, núm. 35 (2018) pp. 63-100. e-ISSN: 2340-2776

http://dx.doi.org/10.12795/rea.2018.i35.03

(c) (i) () 
diversas normativas que se han ido sucediendo en materia de Régimen Local y demarcación territorial municipal que obligan al establecimiento de unos límites territoriales (Copano, L., et al., 2013).

Así, por ejemplo, el Decreto 2697/1966, de 20 de octubre, sobre el régimen para la constitución y funcionamiento de los pueblos construidos por el Instituto Nacional de Colonización como entidades municipales, establece en su artículo 5 b), la necesidad de determinar la demarcación o los límites territoriales que le correspondan. Pero no es necesario retrotraerse a normas ya derogadas, el Real Decreto 1690/1986 en su artículo 45 dicta lo siguiente:

1. Una vez constituida la entidad, sus límites territoriales y la separación patrimonial correspondiente se determinarán, a propuesta de la junta vecinal u órgano colegiado de control, por acuerdo del Ayuntamiento, que habrá de adoptarlo en el plazo de treinta días.

2. Si el Ayuntamiento no adoptase acuerdo en el plazo señalado en el párrafo anterior la Comunidad Autónoma fijará el ámbito territorial de la nueva entidad.

Nos encontramos con diversas situaciones que debieran concretarse en una aprobación de sus límites y su publicación en BOJA, para que el ejercicio de las competencias de estas ELA fuera de pleno derecho:

a) Entidades en cuya normativa de constitución se hace alusión a la delimitación establecida en los Planes de Colonización, estando referida al área de influencia de los poblados, por lo que la misma puede considerase oficiosa pero no oficial ${ }^{18}$ : La Barca de la Florida, Guadalcacín, San Isidro del Guadalete, El Torno, Torrecera, Facinas, Tahivilla, Algallarín, Encinarejo de Córdoba, Fuente Carreteros, La Ropera, Los Villares y La Quintería.

b) Entidades sin delimitación alguna en fuentes históricas documentales, por lo que ateniéndonos a un criterio restrictivo sus límites debieran corresponderse con el suelo urbano y urbanizable: El Centenillo.

c) Entidades sin delimitación oficial que fueron anteriormente municipios independientes, por lo que se conoce de forma aproximada su posible delimitación: Fuente Victoria, Fornes, Picena, Mairena y El Mármol.

\footnotetext{
${ }^{18}$ El producto cartográfico DERA recoge una delimitación aportada por el ayuntamiento para las ELA jerezanas; para las ELA cordobesas, delimitación aportada por la Diputación de Córdoba a partir de las fincas colonizadas; para los municipios de la Zona Regable del Rumblar (provincia de Jaén), la delimitación existente en diversos planos del Instituto Nacional de Colonización; para Facinas y Tahivilla, una delimitación que, según menciona el propio DERA, es la ofrecida por el expediente de constitución.
}

Revista de Estudios Andaluces, núm. 35 (2018) pp. 63- 100. e-ISSN: 2340-2776

http://dx.doi.org/10.12795/rea.2018.i35.03

(c) (1)(9)

Esta obra se distribuye con la licencia Creative Commons Reconocimiento-NoComercialSinObraDerivada 4.0 Internacional 


\subsection{DELIMITACIÓN ADMINISTRATIVA INTERNA DE LA TOTALIDAD DEL TÉRMINO MUNICIPAL}

En la mayor parte de los municipios andaluces que cuentan con una población urbana significativa se constata la existencia de distritos, entendidos como divisiones del núcleo urbano principal para la gestión de aspectos diversos, como podrían ser la participación ciudadana de las asociaciones de vecinos, la información y gestión de expedientes y licencias urbanísticas, etc. Con la misma concepción, pero con diferencias territoriales evidentes, puesto que se exige la delimitación de todo el término municipal, el título $X^{19}$ de la Ley $7 / 1985$ Reguladora de las Bases del Régimen Local, relativo al régimen de organización de los municipios de gran población, establece dos procedimientos (art. 121) para la inclusión de los municipios en dicho régimen:

1. Aquellos cuya población supere los 250.000 habitantes y las capitales de provincia que superen los 175.000 habitantes, cuya inclusión en este régimen se producirá de manera directa e imperativa por legislación estatal.

2. Las capitales autonómicas o sedes de las instituciones autonómicas y las capitales provinciales con independencia de su población, y los municipios de más de 75.000 habitantes que presenten circunstancias económicas, sociales, históricas o culturales especiales, siempre y cuando se decida su inclusión por las asambleas legislativas de la comunidad autónoma a iniciativa de los respectivos ayuntamientos.

Hay que tener en cuenta que para los municipios que ya estén constituidos como de gran población, la circunstancia de pérdida de habitantes por debajo del umbral mínimo no supondrá la privación de las capacidades relativas a este régimen de organización municipal.

La novedad que plantea esta Ley estatal en relación con la delimitación administrativa local es la exigencia planteada a los municipios de gran población (art. 128) para la creación de distritos como divisiones territoriales propias, dotadas de órganos de gestión desconcentrada, para impulsar y desarrollar la participación ciudadana en la gestión de los asuntos municipales y su mejora, sin perjuicio de la unidad de gobierno y gestión del municipio.

En Andalucía, para exigir que la iniciativa que elevara el ayuntamiento a la asamblea legislativa de la comunidad fuera acompañada de una memoria y documentación complementaria adecuada, se aprobó la Ley 2/2008, que regula el acceso de los municipios andaluces al régimen de los de gran población.

\footnotetext{
19 Título introducido por la Ley 57/2003, de 16 de diciembre, de Medidas para la Modernización del Gobierno Local.
}

Revista de Estudios Andaluces, núm. 35 (2018) pp. 63-100. e-ISSN: 2340-2776 http://dx.doi.org/10.12795/rea.2018.i35.03

(c) (i) (3) SinObraDerivada 4.0 Internacional 
Mapa 2. Distritos de los municipios de Sevilla y Málaga.
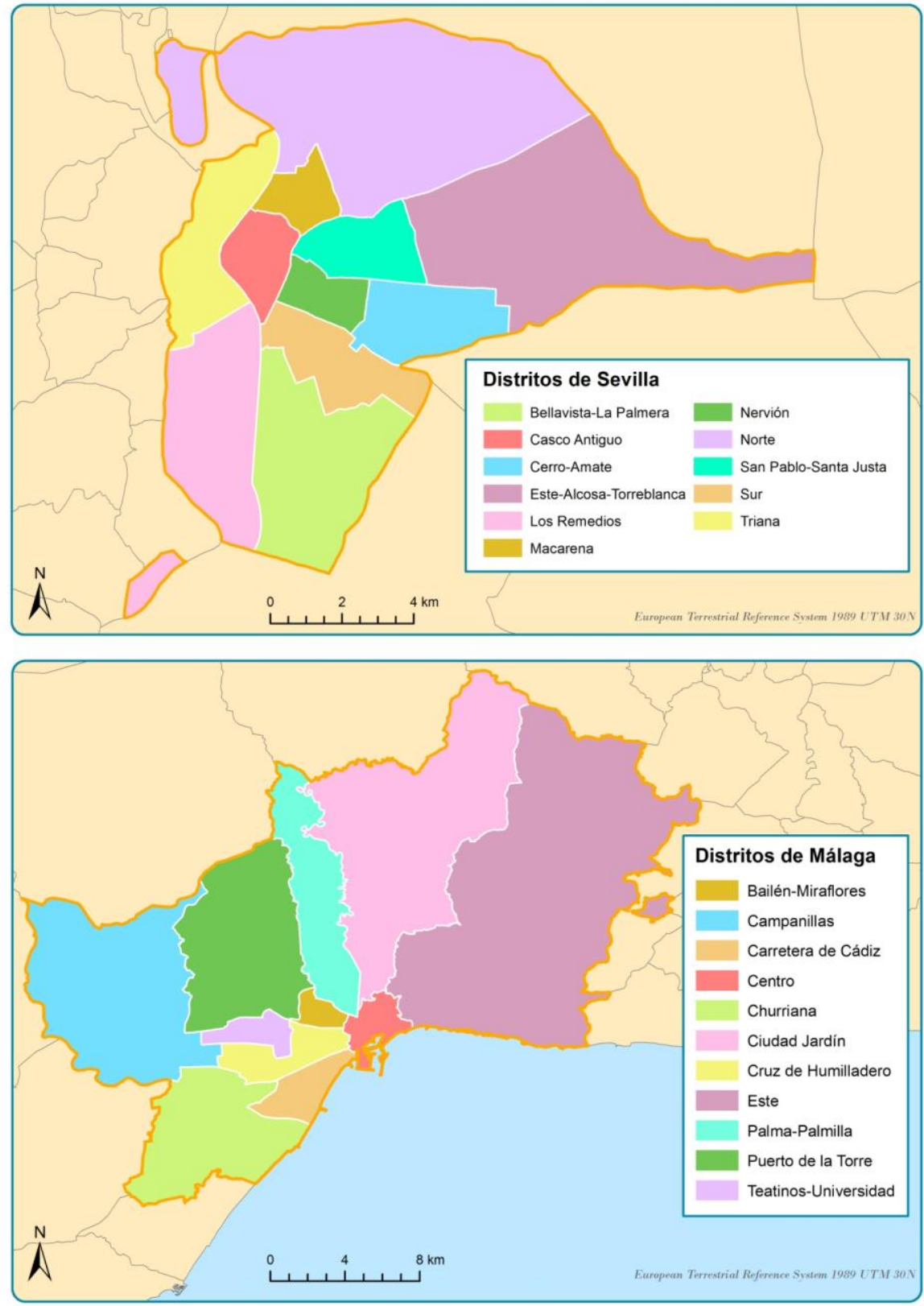

Fuente: Elaboración propia a partir de información municipal.

Existen en la actualidad 10 ayuntamientos andaluces (ver cuadro 3) regulados por el régimen de organización de municipios de gran población que deben poseer una delimitación administrativa de la totalidad de su término municipal, existiendo la posibilidad de que otros municipios puedan alcanzar esta categoría ya sea por su condición como capitales de provincia de menos de 175.000 habitantes (Huelva, Cádiz y Jaén), o por ser municipios con una población superior a 75.000 habitantes

Revista de Estudios Andaluces, núm. 35 (2018) pp. 63- 100. e-ISSN: 2340-2776

http://dx.doi.org/10.12795/rea.2018.i35.03

\section{(c) $($ ) $(9)$}

SinObraDerivada 4.0 Internacional 
Cuadro 3. Municipios de gran población en Andalucía.

\begin{tabular}{|c|c|c|c|c|c|}
\hline MUNICIPIO & $\begin{array}{l}\text { AÑO } \\
\text { ACCESO }\end{array}$ & $\begin{array}{l}\text { TIPO } \\
\text { ACCESO }\end{array}$ & $\begin{array}{l}\text { POBLACIÓN } \\
2015\end{array}$ & $\begin{array}{l}\text { № } \\
\text { DISTRITOS }\end{array}$ & $\begin{array}{l}\text { DISTRITOS } \\
\text { CENSALES }\end{array}$ \\
\hline Sevilla & 2003 & Estatal & 693.878 & 11 & 11 \\
\hline Málaga & 2003 & Estatal & 569.130 & 11 & 11 \\
\hline Córdoba & 2003 & Estatal & 327.362 & 10 & 10 \\
\hline Granada & 2003 & Estatal & 235.800 & 8 & 9 \\
\hline Almería & 2003 & Estatal & 194.203 & 3 & 8 \\
\hline Jerez de la Frontera & 2003 & Autonómico & 212.876 & 7 & 10 \\
\hline Marbella & 2009 & Autonómico & 139.537 & 9 & 4 \\
\hline Dos Hermanas & 2013 & Autonómico & 131.317 & - & 5 \\
\hline Mijas & 2012 & Autonómico & 79.483 & - & 1 \\
\hline Vélez-Málaga & 2012 & Autonómico & 78.166 & - & 5 \\
\hline
\end{tabular}

Fuente: Elaboración propia.

(Algeciras, San Fernando, Roquetas de Mar, El Puerto de Santa María, El Ejido, Chiclana de la Frontera y Fuengirola).

Sin embargo, la realidad es que no se ha llevado a cabo esta delimitación en todos los municipios de gran población (casos de Dos Hermanas, Mijas y Vélez-Málaga), por lo que estarían incumpliendo con el mandato, si bien se trata de los últimos municipios en acceder a este régimen y se encuentran en proceso de elaboración de la reglamentación sobre distritos. En aquellos casos en los que se han conformado unos límites precisos, la delimitación no se ha ajustado a los límites censales ya existentes cuyo principal criterio para su conformación es el poblacional ${ }^{20}$, habiéndose realizado una subdivisión que atiende a otros criterios más vinculados con el ámbito de actuación de las asociaciones de vecinos y la gestión urbanística.

Habría que señalar el caso de Jerez, ya que ha dejado al margen de la delimitación en distritos al territorio relativo a las ELA, cuando la normativa exige que esta subdivisión sea de todo el municipio ${ }^{21}$, por lo que, a pesar de la existencia de competencias descentralizadas $y$, por tanto, propias, en estos territorios, la población residente no tendría a su alcance las mismas capacidades para canalizar su participación en los asuntos municipales.

\footnotetext{
${ }^{20}$ La sección censal se define como un territorio continúo habitado por una población entre 500 y 2.500 habitantes, perfectamente delimitado por accidentes del territorio, geográficos y/o urbanísticos, en el que cada vivienda o habitante queda incluido dentro de una única sección.

${ }^{21}$ En el artículo 123 c) de la Ley 7/1985 se menciona expresamente que las atribuciones del pleno, entre otras, serán la aprobación y modificación de los reglamentos de naturaleza orgánica, entre los que se encuentra la división del municipio en distritos.
}

Revista de Estudios Andaluces, núm. 35 (2018) pp. 63-100. e-ISSN: 2340-2776 http://dx.doi.org/10.12795/rea.2018.i35.03

(c) $(i) \Theta($

Esta obra se distribuye con la licencia Creative Commons Reconocimiento-NoComercialSinObraDerivada 4.0 Internacional 
Por otro lado, los municipios que ya han realizado su delimitación en distritos también han creado los órganos de gestión desconcentrada ${ }^{22}$ a los que obliga la legislación, que deben estar presididos por un concejal y tener asignadas una serie de funciones que pueden variar según el reglamento orgánico sobre participación ciudadana de cada ayuntamiento.

\subsection{POSIBILIDADES SEGREGACIONISTAS DE LAS ENTIDADES SUBMUNICIPALES}

Los fenómenos segregacionistas o secesionistas experimentan un importante auge con el inicio del período constitucional, en gran parte como reacción a la tendencia concentradora que se desarrolló con fuerza durante la etapa franquista ${ }^{23}$ (Ventura, J., 1991), alcanzando la condición de municipio las siguientes poblaciones ${ }^{24}$ : El Ejido (1983, Dalías), Cuevas del Campo (1983, Zújar), La Mojonera (1984, Felix), Cañada Rosal (1986, La Luisiana), Zagra (1986, Loja), Torremolinos (1988, Málaga), El Cuervo ${ }^{25}$ (1992, Lebrija), Benalup ${ }^{26}$ (1991, Medina-Sidonia), Villafranco del Guadalquivir ${ }^{27}$ (1994, La Puebla del Río), San José del Valle (1995, Jerez de la Frontera) y Arroyo del Ojanco (2001, Beas de Segura).

Con la entrada en vigor de la Ley 7/1993, de 27 de julio, Reguladora de la Demarcación Municipal de Andalucía (LRDMA), el legislador autonómico expresaba su voluntad de alterar lo menos posible la realidad territorial andaluza mediante la creación de nuevos municipios, subrayando la relevancia de la figura de la Entidad Local Autónoma (ELA) como un instrumento adecuado para canalizar las aspiraciones de autogestión que pudieran tener los vecinos de una localidad. Sin embargo, en muchas ocasiones, las ELA consideraron este régimen jurídico como transitorio respecto al que realmente aspiraban alcanzar, que no era otro que la condición de nuevo municipio por segregación del municipio en cuyo término se hallaban.

\footnotetext{
${ }^{22}$ Denominados como Juntas Municipales de Distrito en Sevilla, Málaga, Córdoba, Granada, Almería y Marbella. En Jerez de la Frontera hablaríamos de Consejo Territorial de Distrito, aunque en el artículo 102 de su reglamento matiza que pueden "coexistir más de un Consejo dentro de los límites asignados a un mismo Distrito, pero sin que en ningún caso pueda abarcar zonas comprendidas en dos o más Distritos". En el caso de Córdoba, el Consejo de Distrito sería una subdivisión de los distritos; nombrados en Granada como Asociaciones de Vecinos.

${ }^{23}$ En la década de los setenta del siglo pasado se redujo el número de municipios andaluces en 35 (Ventura, J., 1991).

${ }^{24}$ Segregaciones anteriores a la vigencia de la Ley /1993, de 27 de julio, Reguladora de la Demarcación Municipal de Andalucía (LRDMA).

25 En 1993 cambia su denominación por El Cuervo de Sevilla.

26 Desde el año 1999 denominado Benalup-Casas Viejas.

27 Cambia su denominación en 2000 por Isla Mayor.
}

Revista de Estudios Andaluces, núm. 35 (2018) pp. 63- 100. e-ISSN: 2340-2776

http://dx.doi.org/10.12795/rea.2018.i35.03

(c) (1) ()

SinObraDerivada 4.0 Internacional 
En este sentido, la propia LRDMA suavizaba las rigurosas exigencias contempladas en el artículo 8 en aquellos supuestos en los que el proyecto de segregación tuviera por objeto el ámbito territorial que hubiera accedido a la condición de ELA al menos 5 años atrás de la incoación del procedimiento. Concretamente, el rigor se minoraba en cuanto a la exigencia del montante poblacional mínimo (la cifra de 4.000 habitantes exigidos con carácter general quedaba reducida a 2.500), así como en cuanto a la distancia mínima de suelo no urbanizable con respecto al núcleo en el que radicaba la capitalidad del municipio (frente a los 7.500 metros establecidos con carácter general, se exigían tan solo 5.000 metros). Aún así, el único núcleo poblacional que logró acceder a la condición de municipio durante el período de vigencia de esta normativa fue Villanueva de la Concepción, acogiéndose a la reducción de las exigencias recogidas en el artículo 8.4, mediante el Decreto 63/2009 por el que aprobó su segregación de Antequera y la constitución en nuevo municipio. En cuanto a Balanegra, logró la segregación del municipio de Berja (Almería) por medio del Decreto 144/2015, de 2 de junio, que aprueba la creación del municipio de Balanegra por segregación del término municipal de Berja, cuando la LRDMA ya había sido derogada.

La actual normativa andaluza sobre régimen local, La Ley 5/2010 de Autonomía Local de Andalucía (LAULA), en su artículo 93.2, deja claro el carácter excepcional de la creación de un nuevo municipio por segregación de otro ya existente, que se realizará sobre la base de núcleos de población, necesitando "la conformidad expresa, acordada por mayoría absoluta, del pleno del ayuntamiento del municipio que sufre la segregación", así como la concurrencia de, al menos, las siguientes circunstancias:

a) La existencia de motivos permanentes de interés público relacionados con la planificación territorial de Andalucía.

b) Que el territorio del nuevo municipio cuente con unas características que singularicen su propia identidad sobre la base de razones históricas, sociales, económicas, laborales, geográficas y urbanísticas.

c) Que entre los núcleos principales de población del municipio matriz y del territorio que pretende la segregación exista una notable dificultad de acceso caracterizada por la distancia, orografía adversa, duración del trayecto en vehículo automotor, carencia de servicio público de transporte de viajeros $u$ otras de similar naturaleza.

d) Que el nuevo municipio pueda disponer de los recursos necesarios para el cumplimiento de las competencias municipales que como mínimo venía ejerciendo el municipio del que se segrega $y$, en todo caso, los servicios previstos como básicos por la ley. Dichos recursos deben estar relacionados con la capacidad financiera de la vecindad del nuevo municipio y la riqueza imponible de su término municipal.

e) Que el nuevo municipio cuente con un territorio que permita atender a sus necesidades demográficas, urbanísticas, sociales, financieras y de instalación de los servicios de competencia municipal. 
f) Que el nuevo municipio pueda garantizar la prestación de los servicios públicos con el mismo nivel de calidad que el alcanzado por el municipio matriz en el territorio base de la segregación.

g) Que el municipio o municipios matrices no se vean afectados de forma negativa en la cantidad y calidad de prestación de los servicios de su competencia, ni privados de los recursos necesarios para la prestación de los servicios mínimos establecidos legalmente.

Por tanto, se eliminan las exigencias cuantitativas en cuanto al volumen poblacional del núcleo que pretenda segregarse, así como la distancia mínima de suelo no urbanizable de dicho núcleo respecto al que ostente la capitalidad del municipio, si bien el principal obstáculo al que deben enfrentarse es a la exigencia de la conformidad de la mayoría absoluta del pleno del ayuntamiento del municipio que sufre la segregación, lo que, en principio, podría parecer como de difícil solución puesto que no resultaría fácil obtener dicha conformidad, ya que supondría una merma de los recursos y del patrimonio municipal. No obstante, desde la entrada en vigor de la LAULA han sido 7 los nuevos municipios surgidos por segregación: Valderrubio, Montecorto, Dehesas Viejas, Serrato, Játar, Domingo Pérez de Granada y Balanegra $^{28}$.

La Ley 27/2013, de 27 de diciembre, de Racionalización y Sostenibilidad de la Administración Local viene a endurecer las condiciones para la creación de nuevos municipios por segregación de otros ya existentes, estableciendo un umbral poblacional de 5.000 habitantes (art. 13), lo que implicaría que de los 1.958 núcleos secundarios existentes en Andalucía, solo 34 de los mismos $(1,7 \%)$ podrían cumplir con el mencionado requisito demográfico. Habría que tener en cuenta, además, que la mayor parte de estos núcleos secundarios son realmente urbanizaciones costeras muy próximas a su cabecera municipal o al núcleo principal de otro municipio, careciendo de identidad propia y diferenciada, por lo que en la práctica se pone freno a las segregaciones. En cuanto a las ELA existentes, solo Guadalcacín, situado en el término municipal de Jerez de la Frontera e integrado dentro del suelo urbano del mismo, superaría este límite poblacional si contamos la población de su diseminado, alcanzando los 5.256 habitantes.

El nuevo requisito introducido por esta normativa de carácter básico fue de gran relevancia por hallarse en tramitación en la Administración Autonómica una serie de iniciativas de creación de nuevos municipios, ninguna de las cuales alcanzaba esa cifra mínima de habitantes contemplada en la nueva norma, por lo que se formuló consulta

\footnotetext{
${ }^{28}$ Como ya se ha indicado anteriormente, en 2015 Balanegra se segrega de Berja, aunque la normativa de referencia es la Ley /1993, de 27 de julio, Reguladora de la Demarcación Municipal de Andalucía (LRDMA).
}

Revista de Estudios Andaluces, núm. 35 (2018) pp. 63- 100. e-ISSN: 2340-2776

http://dx.doi.org/10.12795/rea.2018.i35.03

(c) (1) (9)

SinObraDerivada 4.0 Internacional 
Cuadro 4. Municipios segregados desde la entrada en vigor de la LAULA (2010).

\begin{tabular}{|c|c|c|c|}
\hline $\begin{array}{l}\text { NUEVO } \\
\text { MUNICIPIO }\end{array}$ & POBLACIÓN & $\begin{array}{l}\text { NORMA DE } \\
\text { REFERENCIA }\end{array}$ & CONSTITUCIÓN OFICIAL \\
\hline $\begin{array}{l}\text { Valderrubio } \\
\text { (Granada) }\end{array}$ & $\begin{array}{l}2.110 \\
(01 / 01 / 2013)\end{array}$ & LAULA & $\begin{array}{l}\text { Decreto } 237 / 2013 \text {, de } 17 \text { de diciembre, se } \\
\text { aprueba la creación del municipio de } \\
\text { Valderrubio por segregación del término } \\
\text { municipal de Pinos Puente (BOJA no246, de } \\
18 \text { de diciembre de 2013). }\end{array}$ \\
\hline $\begin{array}{l}\text { Montecorto } \\
\text { (Málaga) }\end{array}$ & $\begin{array}{l}649 \\
(01 / 01 / 2014)\end{array}$ & LAULA & $\begin{array}{l}\text { Decreto } 135 / 2014 \text {, de } 30 \text { de septiembre, se } \\
\text { aprueba la creación del municipio de } \\
\text { Montecorto, por segregación del término } \\
\text { municipal de Ronda (BOJA no 203, de } 30 \text { de } \\
\text { septiembre de 2014). }\end{array}$ \\
\hline $\begin{array}{l}\text { Dehesas Viejas } \\
\text { (Granada) }\end{array}$ & $\begin{array}{l}766 \\
(01 / 01 / 2014)\end{array}$ & LAULA & $\begin{array}{l}\text { Decreto } 140 / 2014 \text {, de } 7 \text { de octubre, se } \\
\text { aprueba la creación del municipio de Dehesas } \\
\text { Viejas, por segregación del término municipal } \\
\text { de Iznalloz (BOJA no 207, de } 23 \text { de octubre de } \\
\text { 2014). }\end{array}$ \\
\hline Serrato (Málaga) & $\begin{array}{l}500 \\
(01 / 01 / 2014)\end{array}$ & LAULA & $\begin{array}{l}\text { Decreto } 167 / 2014 \text {, de } 2 \text { de diciembre, se } \\
\text { aprueba la creación del municipio de Serrato, } \\
\text { por segregación del término municipal de } \\
\text { Ronda (BOJA no247, de } 19 \text { de diciembre de } \\
\text { 2014). }\end{array}$ \\
\hline Játar (Granada) & $\begin{array}{l}624 \\
(01 / 01 / 2015)\end{array}$ & LAULA & $\begin{array}{l}\text { Decreto } 62 / 2015 \text {, de } 3 \text { de febrero, se aprueba } \\
\text { la creación del municipio de Játar, por } \\
\text { segregación del término municipal de Arenas } \\
\text { del Rey (BOJA no34, de } 19 \text { de febrero de } \\
\text { 2015). }\end{array}$ \\
\hline $\begin{array}{l}\text { Domingo Pérez } \\
\text { de Granada } \\
\text { (Granada) }\end{array}$ & $\begin{array}{l}857 \\
(01 / 01 / 2015)\end{array}$ & LAULA & $\begin{array}{l}\text { Decreto } 105 / 2015 \text {, de } 17 \text { de marzo, se } \\
\text { aprueba la creación del municipio de Domingo } \\
\text { Pérez de Granada, por segregación del } \\
\text { término municipal de Iznalloz (BOJA no66, de } \\
8 \text { de abril de 2015). }\end{array}$ \\
\hline $\begin{array}{l}\text { Balanegra } \\
\text { (Almería) }\end{array}$ & $\begin{array}{l}2.804 \\
(01 / 01 / 2015)\end{array}$ & LRDMA & $\begin{array}{l}\text { Mediante Decreto } 144 / 2015 \text {, de } 2 \text { de junio, se } \\
\text { aprueba la creación del municipio de } \\
\text { Balanegra por segregación del término } \\
\text { municipal de Berja (BOJA no } 118 \text {, de } 19 \text { de } \\
\text { junio de 2015). }\end{array}$ \\
\hline
\end{tabular}

Fuente: Elaboración propia a partir de los decretos de creación de nuevos municipios (2017).

al Ministerio de Hacienda y Administraciones Públicas con objeto de que tal organismo emitiese informe acerca de la procedencia o no de aplicar tal exigencia a los procedimientos iniciados con anterioridad a la Ley de Racionalización y Sostenibilidad de la Administración Local (LRSAL), concluyéndose, finalmente, que los procedimientos se resolverán de acuerdo con la normativa vigente en el momento de su incoación. De esta forma, ninguno de los municipios que alcanzaron su independencia con posterioridad a la LRSAL, tuvieron que acogerse al requisito del mínimo poblacional de 5.000 habitantes.

Revista de Estudios Andaluces, núm. 35 (2018) pp. 63-100. e-ISSN: 2340-2776 http://dx.doi.org/10.12795/rea.2018.i35.03

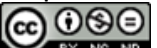


El estado de la cuestión en cuanto a los procedimientos de creación de nuevos municipios en Andalucía, a partir de Entidades Locales Autónomas, es el siguiente:

- Existe un procedimiento de segregación (San Martín del Tesorillo, en el término de Jimena de la Frontera) iniciado con anterioridad a la entrada en vigor de la LAULA, incoado a instancia vecinal, cuya normativa de referencia es la Ley 7/1993, así como el Decreto 185/2005, por lo que la junta vecinal de la ELA ostenta plena legitimación para instar la segregación. El principal inconveniente en cuanto a la segregación es la falta de garantías económicas (elevada deuda) para que el nuevo municipio pueda cumplir con sus competencias, así como la inexistencia de un pronunciamiento expreso del ayuntamiento matriz respecto a que no sufriría un quebranto de sus recursos económicos motivado por la segregación.

- Se están tramitando 7 procedimientos de segregación (La Guijarrosa, Fuente Carreteros, Fornes, Tharsis, La Zarza-Perrunal y El Palmar de Troya) según las previsiones de la LAULA, circunstancia que supone que su incoación se ha llevado a cabo por los propios municipios matrices que, mediante acuerdo adoptado por mayoría absoluta de sus respectivos plenos, así lo han decidido.

- Las Entidades Locales Autónomas de La Barca de la Florida, Torrecera y Torrenueva han intentado que la tramitación se impulse de oficio por la Dirección General de Administración Local o bien por la Diputación Provincial, tratando que la fase autonómica se incoe justo antes de la entrada en vigor de la Ley 27/2013, para así poder eludir la exigencia de los 5.000 habitantes contemplada en esta norma.

- Sobre Ventas de Zafarraya y Carchuna-Calahonda ya se han tramitado iniciativas de segregación en sentido desestimatorio, o en las que tal iniciativa ha terminado con un desistimiento expreso de la parte interesada.

- Por último, se tiene constancia de las pretensiones segregacionistas, o de iniciación de debates al respecto, en las ELA de Mairena y Picena respecto al municipio de Nevada.

\section{CONCLUSIONES}

En Andalucía, existe una realidad territorial submunicipal compuesta por entidades poblacionales que demandan un mayor nivel dotacional y de servicios al ayuntamiento matriz del que dependen, orientándose sus reivindicaciones hacia la consecución de la segregación y a la creación de un municipio independiente, o simplemente hacia la constitución de una entidad que les permita gestionar sus intereses, ya sea adquiriendo competencias propias (descentralización) conformando Entidades Locales Autónomas, o por medio de la delegación de competencias en órganos de gestión desconcentrada.

Revista de Estudios Andaluces, núm. 35 (2018) pp. 63- 100. e-ISSN: 2340-2776

http://dx.doi.org/10.12795/rea.2018.i35.03

(c) (1) (9)

Esta obra se distribuye con la licencia Creative Commons Reconocimiento-NoComercialSinObraDerivada 4.0 Internacional 
La normativa sobre autonomía local concede a los municipios la potestad de autoorganización de su territorio, ya sea de forma desconcentrada o descentralizada. Esto supone una verdadera oportunidad para mejorar y acercar la acción administrativa a la población, ser más eficientes en la prestación de los servicios públicos y facilitar la participación ciudadana; sin embargo, también supone asumir responsabilidades y obligaciones en relación a la ordenación territorial de su municipio.

Tomar una decisión respecto al carácter desconcentrado o descentralizado de las circunscripciones territoriales, aunque importante para establecer el tipo de competencias asumidas por cada entidad, no es lo más interesante en este discurso, ya que aunque la descentralización supone poseer una mayor autonomía (por conllevar competencias consideradas como propias), la desconcentración puede significar un mayor número de competencias que, aunque no sean propias sino delegadas, permiten una gestión más eficaz.

Es conveniente, por tanto, que los municipios, en virtud de su plena autonomía, para organizarse internamente, realicen un exhaustivo análisis territorial, que debe incluir la determinación de los núcleos de población existentes y de aquellos asentamientos de carácter diseminado, teniendo presente las diversas características históricas, geográficas, sociales, económicas, culturales o administrativas que revelasen unos intereses colectivos peculiares.

Actualmente, algunas realidades poblacionales ostentan la titularidad de competencias propias, gozando de personalidad jurídica mediante la adopción de la figura de Entidad Local Autónoma, incluso muchas poseen una delimitación clara y oficial respecto al ámbito territorial donde ejercer sus competencias; no así una parte de ellas, que llevan a cabo sus funciones en un ámbito exclusivamente urbano, limitándose al contorno de su núcleo de población (en ocasiones en más de un núcleo). Por otro lado, casi todas las EATIMES que no sufrieron un período de adaptación para su conversión en ELA según la Ley de Demarcación Municipal de Andalucía (ya derogada), a pesar de no poseer un ámbito territorial bien definido, no limitan su ámbito de actuación al contorno de sus núcleos, estando su alcance aumentado a aquellas parcelas destinadas a la actividad agrícola de sus pobladores.

También nos encontramos con núcleos de población que poseen competencias delegadas de sus ayuntamientos, en ocasiones casi tan amplias como las que pueden ostentar las ELA, aunque solo las ejercen para sus vecinos y no para un territorio dado. Otros, sin embargo, a pesar de no tener competencias asignadas, poseen un alto grado de asociacionismo, siendo sociedades muy participativas y reivindicativas, llegando a ejecutar competencias municipales que, a pesar de no estar delegadas, el ayuntamiento deja en manos de la comunidad (como por ejemplo los festejos y las actividades culturales).

Revista de Estudios Andaluces, núm. 35 (2018) pp. 63-100. e-ISSN: 2340-2776 http://dx.doi.org/10.12795/rea.2018.i35.03

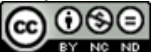




\section{BIBLIOGRAFÍA}

Astillero, J.M. (2001). La delimitación del ámbito territorial de una entidad local autónoma: método de análisis y propuestas. Universidad de Sevilla, Sevilla (inédito).

Beato, M. (1988). El ámbito territorial en las entidades locales creadas por motivo de colonización interior. Anuario de la Facultad de Derecho, 6, pp. 281-311.

Benito, J. y de la Vega, S. (2003). Consideraciones geográficas sobre la superficie de los municipios de Andalucía. Espacio y Tiempo: Revista de Ciencias Humanas, 17, 9-28.

Burgueño, J. (2001). Geografía y Administración. Proyectar territorios en el siglo XXI. Boletín de la Asociación de Geógrafos Españoles, no 32, pp. 191-207.

Carta Europea de la Autonomía Local. Boletín Oficial del Estado, de 24 de febrero de 1989, núm. 47.

Constitución Española, 1978. Boletín Oficial del Estado, de 29 de diciembre de 1978, núm. 311.

Consejería de Gobernación y Justicia (2010). La demarcación municipal en Andalucía. Dirección General de Administración Local. Sevilla (inédito).

Copano, L. (2009). Proceso de comarcalización y descentralización administrativa municipal del alfoz jerezano. La influencia del poblamiento. Trabajo Fin de Experto Universitario en Planificación y Desarrollo a Escala Subregional (inédito), 105 pp.

Copano Ortiz, L. (2011). Desconcentración y descentralización administrativa en Andalucía.Criterios para la delimitación de unidades territoriales inferiores al municipio: aplicación en el término de Jerez de la Frontera. (Trabajo fin de máster inédito). [En línea] Universidad de Sevilla, Sevilla, $214 \mathrm{pp}$. <https://idus.us.es/xmlui/handle/11441/42030> [16 de octubre de 2017].

Copano, L. y Ventura, J. (2013). La organización del territorio submunicipal en Andalucía. Criterios administrativos para su delimitación. Revista de Estudios Regionales, 98, 155-191.

Cruz, J. (1996). El mapa de la política de colonización en Andalucía. Investigaciones Geográficas, 16, 21-34. https://doi.org/10.14198/INGEO1996.16.01

Revista de Estudios Andaluces, núm. 35 (2018) pp. 63- 100. e-ISSN: 2340-2776 http://dx.doi.org/10.12795/rea.2018.i35.03 (c) (1) (9) SinObraDerivada 4.0 Internacional 
Decreto 185/2005, de 30 de agosto, por el que se aprueba el Reglamento de Demarcación Municipal de Andalucía y del Registro Andaluz de Entidades Locales. Boletín Oficial de la Junta de Andalucía, de 23 de septiembre de 2005, núm. 187.

García, J.A. (2002). La administración local en el constitucionalismo histórico español. Anales de la Facultad de Derecho, 19, 23-40.

González, J. (1949). La colonización de zonas regables. La Ley de 21 de Abril de 1949. Revista de Estudios Jurídicos, 48, 154-170.

Guirado, C. (1991). Las entidades locales menores: antecedentes legislativos y regulación actual. Régimen murciano. Anales de Derecho, 11, 237-258.

Instituto Nacional de Estadística (2017). Nomenclátor: Población del Padrón Continuo por Unidad Poblacional [En línea] <http://www.ine.es/nomen2/index.do> [22 de noviembre de 2017].

Leal, A. (1955). Régimen administrativo de los nuevos pueblos creados por el Instituto Nacional de Colonización. Revista de Estudios Agrosociales, 10, 89-112.

Ley $7 / 1985$, de 2 de abril, Reguladora de las Bases del Régimen Local. Boletín Oficial del Estado, de 3 de abril de 1985, núm. 80.

Ley 7/1993, de 27 de julio, Reguladora de la Demarcación Municipal de Andalucía. Boletín Oficial de la Junta de Andalucía, de 7 de agosto de 1993, núm. 86.

Ley $57 / 2003$, de 16 de diciembre, de medidas para la modernización del gobierno local. Boletín Oficial del Estado, de 17 de diciembre de 2003, núm. 301.

Ley 2/2008, que regula el acceso de los municipios andaluces al régimen de los municipios de gran población. Boletín Oficial de la Junta de Andalucía, de 24 de diciembre de 2008, núm. 255.

Ley 5/2010, de 11 de junio, de Autonomía Local de Andalucía. Boletín Oficial de la Junta de Andalucía, de 23 de junio de 2010, núm. 122.

Ley 27/2013, de 27 de diciembre, de racionalización y sostenibilidad de la Administración Local. Boletín Oficial del Estado, de 30 de diciembre de 2013, núm. 312.

Ley Orgánica 2/2007, de 19 de marzo, de reforma del Estatuto de Autonomía para Andalucía. Boletín Oficial de la Junta de Andalucía, de 20 de marzo de 2007, núm. 56. 
Ley Orgánica 6/1981, de 30 de diciembre, Estatuto de Autonomía para Andalucía. Boletín Oficial de la Junta de Andalucía, de 1 de febrero de 1982, núm. 2.

Medina, J.A. (2010). El componente espacial del municipio y su administración a la luz de la potestad de autoorganización. Sevilla (inédito).

Orden de 13 de junio de 1997, por la que se regula el proceso de adaptación de las Entidades de Ámbito Territorial Inferior al Municipio en Entidades Locales Autónomas. Boletín Oficial de la Junta de Andalucía, de 5 de julio de 1997, núm. 77.

Orduña, E. (2012). El municipio constitucional en la España de 1812. UNED Revista de Derecho Político, 83, 400-437.

Parejo, L. (2008). La autonomía local desde el punto de vista de su realización efectiva. Revista electrónica CEMCI, 1 Oct-Dic, 1-37.

Pallarès, A. (2009). Aproximación al régimen jurídico de las entidades de ámbito territorial inferior al municipio de Cataluña. Revista de Estudios de la Administración Local y Autonómica, 309, 135-155.

Pereira, D., Fernández, F. y Ocón, B. (2004). Las zonas rurales en España. Un diagnóstico desde la perspectiva de las desigualdades territoriales y los cambios sociales y económicos. Madrid: Cáritas Española, 536 pp.

Pérez, M.M. (2010). Las Entidades Locales Autónomas en la Ley de Autonomía Local de Andalucía (LAULA). El consultor de los Ayuntamientos y de los juzgados, 24, 3490-3508.

Reguera, A. (1986). Transformación del espacio y política de colonización: el Bajo Guadalquivir. León: Diputación Provincial de León, 200 pp.

Real Decreto 1690/1986, de 11 de julio, por el que se aprueba el Reglamento de Población y Demarcación Territorial de las Entidades Locales. Boletín Oficial del Estado, de 14 de agosto de 1986, núm. 194.

Real Decreto 2612/1996, de 20 de diciembre, por el que se modifica el Reglamento de Población y Demarcación Territorial de las Entidades Locales aprobado por el Real Decreto 1690/1986, de 11 de julio. Boletín Oficial del Estado, de 16 de enero de 1996, núm. 14. 
Real Decreto Legislativo 781/1986, de 18 de abril, por el que se aprueba el Texto Refundido de las Disposiciones legales vigentes en materia de Régimen Local. Boletín Oficial del Estado, de 22 de abril de 1986, núm. 96.

Subdirección General de Estudios y Sistemas de Información Local (2009). Estudio sobre el Registro de Entidades Locales. [En línea] Catálogo de Publicaciones de la Secretaría General Técnica del Ministerio de Política Territorial, 30 pp. < http://www.sefp.minhafp.gob.es/dam/es/web/publicaciones/centro_de_publicacione s_de_la_sgt/Otras_Publicaciones/parrafo/01111111111111/text_es_files/EstudioRegistro-Entidades-Locales-INTERNET.pdf> [23 de noviembre de 2017]. NIPO: 830-09002-3.

Teijeiro, M.E. (1996). Datos para el estudio de un fenómeno de descentralización administrativa: los poblados de colonización como entidades locales menores. En I Congreso de Ciencia Regional de Andalucía: Andalucía en el umbral del siglo XXI (pp. 27-33) (comunicaciones). Jerez.

Ventura, J. (1990). Pasado y presente de la política de población y poblamiento en Andalucía. En G. Cano García (Dir. y Coord.) Geografía de Andalucía, volumen VII, Política territorial y organización del espacio en Andalucía (pp.247-269). Cádiz: Ed. Tartessos.

Ventura, J. (1991). Tensiones en el poblamiento andaluz y problemas de administración territorial. Revista de Estudios Andaluces, 16, 93-113.

Ventura, J. y Ayala, J. (1987). Concentración y dispersión: características del poblamiento andaluz. En G. Cano García (Dir. y Coord.) Geografía de Andalucía, volumen III, Población, Poblamiento y Ciudades de Andalucía (pp.207-257). Madrid: Ed. Tartessos. 